\title{
Evolution of Wearable Devices with Real-Time Disease Monitoring for Personalized Healthcare
}

\author{
Kyeonghye Guk ${ }^{1,2}$, Gaon Han ${ }^{1,2}$, Jaewoo Lim ${ }^{1,2}$, Keunwon Jeong ${ }^{1,2}$, Taejoon Kang 1,2®, \\ Eun-Kyung Lim ${ }^{1,2, * \mathbb{D}}$ and Juyeon Jung ${ }^{1,2, *}$ \\ 1 BioNano Technology Research Center, Korea Research Institute of Bioscience and Biotechnology (KRIBB), \\ 125 Gwahak-Ro, Yuseong-Gu, Daejeon 34141, Korea; will1024@kribb.re.kr (K.G.); \\ 7chawon@kribb.re.kr (G.H.); zeuyim5052@kribb.re.kr (J.L.); kwjeong@kribb.re.kr (K.J.); \\ kangtaejoon@kribb.re.kr (T.K.) \\ 2 Department of Nanobiotechnology, KRIBB School of Biotechnology, University of Science and \\ Technology (UST), 217 Gajeong-Ro, Yuseong-Gu, Daejeon 34113, Korea \\ * Correspondence: eklim1112@kribb.re.kr (E.-K.L.); jjung@kribb.re.kr (J.J.); Tel.: +82-42-860-4192 (J.J.)
}

Received: 15 April 2019; Accepted: 22 May 2019; Published: 29 May 2019

check for updates

\begin{abstract}
Wearable devices are becoming widespread in a wide range of applications, from healthcare to biomedical monitoring systems, which enable continuous measurement of critical biomarkers for medical diagnostics, physiological health monitoring and evaluation. Especially as the elderly population grows globally, various chronic and acute diseases become increasingly important, and the medical industry is changing dramatically due to the need for point-of-care (POC) diagnosis and real-time monitoring of long-term health conditions. Wearable devices have evolved gradually in the form of accessories, integrated clothing, body attachments and body inserts. Over the past few decades, the tremendous development of electronics, biocompatible materials and nanomaterials has resulted in the development of implantable devices that enable the diagnosis and prognosis through small sensors and biomedical devices, and greatly improve the quality and efficacy of medical services. This article summarizes the wearable devices that have been developed to date, and provides a review of their clinical applications. We will also discuss the technical barriers and challenges in the development of wearable devices, and discuss future prospects on wearable biosensors for prevention, personalized medicine and real-time health monitoring.
\end{abstract}

Keywords: wearable devices; real-time monitoring; personal health; biosensor; portable devices; attachable devices; implantable devices; personal health; point-of-care; physiological signals

\section{Introduction}

Today, with the increase in the elderly population, the medical industry has changed dramatically, with a focus on the development of biosensors that enable real-time health monitoring, prevention and personalized medicine for a variety of chronic and acute diseases. Point-of-care technology (POCT) provides rapid and patient-centered diagnostics, especially for those with limited access to health services, while conventional disease diagnostic tests commonly used in laboratories and hospitals are time-consuming and costly, and require highly trained personnel. As healthcare regimes shift more toward personalized medicine, globally wearable sensors will have an average compound annual growth rate (CAGR) of approximately 38\% from 2017 to 2025, among which the development of the smart watch is expected to grow at a particularly high rate [1].

Wearable biosensors have received tremendous attention over the past decade, mainly concentrated in the healthcare industry, which attempts to apply physical signals such as heart rate, blood pressure, skin temperature, respiratory rate and body motion to extract clinically relevant information [2-5]. 
Wearable devices are real-time and noninvasive biosensors allowing for the continuous monitoring of individuals, and thus provide sufficient information for determining health status, and even preliminary medical diagnosis. In addition, wearable biosensors allow health care providers to monitor the physiological traits of patients after therapeutics or treatments.

Wearable biosensors refer to biological sensors, including watches, clothing, bandages, glasses, contact lenses and rings, that are conveniently attached to a person's body, and provide a function that distinguishes them from existing devices in terms of portability, ease of use and environmental adaptability [6-8]. Wearable devices have gradually been developed in the form of accessories, integrated clothing, body attachments and body insertions (Figure 1A) [9,10]. Over the past few decades, the tremendous advance in electronic, biocompatible materials and nanomaterials has led to the development of implantable devices that enable diagnosis and prognosis through small sensors and biomedical devices, greatly improving the quality and efficacy of health care. Despite motion artifacts, one of the major problems associated with wearable sensors is the development of stretchable and skin-attachable electronic devices that can continuously and unobtrusively monitor human activity and vital signs without any disruption or restriction by the user's movement. The first implantable medical device developed was a pacemaker for arrhythmia patients in 1958 [11]. Since then, various types of pacemakers and implantable cerebellar stimulators have been developed and used. In recent years, flexible and stretchable electronic devices have allowed implantable systems to be deployed in the deep brain, the intravascular area, the intracardiac area and even the single-cell interior [12,13]. At present, wearable devices are driven by their own receiver, feature a signal processor, and are battery-powered, enabling them to operate as a "microcomputer" and allowing for the connection of all processes, from information collection and processing, to communication and power supply. Wearable devices connect to other smart devices via Bluetooth, infrared, radio-frequency identification (RFID) and near-field communication (NFC) technology. Together, this connectivity has led to the development of wearable systems for remote and long-term patient monitoring in homes and communities that were previously impossible (Figure 1B). This capability is expected to make a significant contribution to reducing medical and healthcare costs in countries with a large population of elderly people. This article provides a review of the evolutionary clinical applications of commercially available, newly emerging, technically challenging and future wearable devices. We also discuss the technical barriers and challenges of currently available biosensors and the future prospects for emerging biosensors.
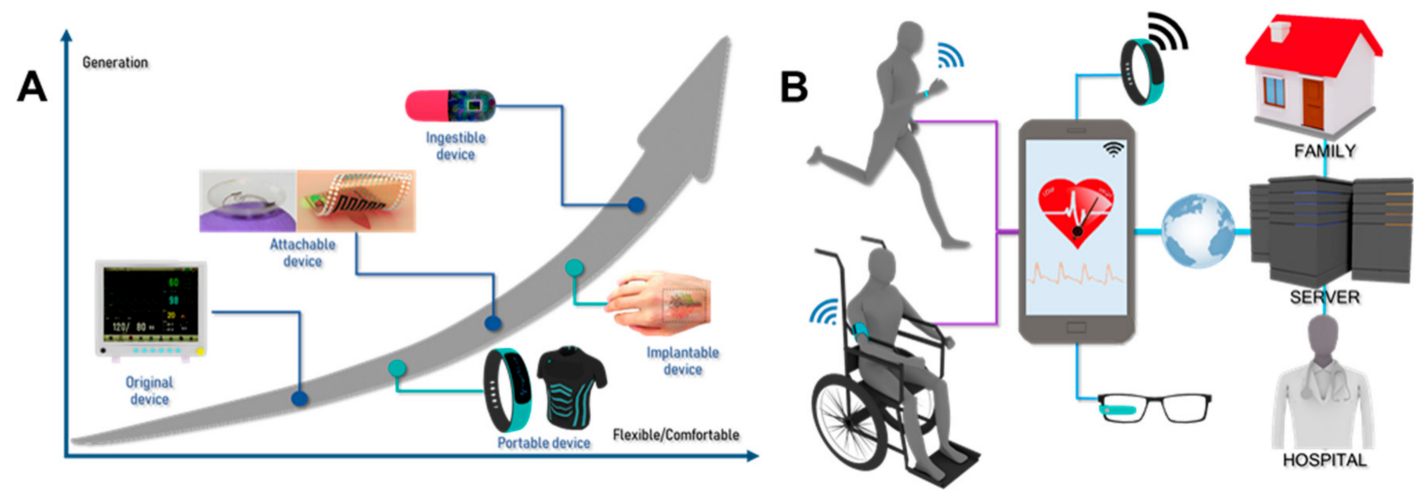

Figure 1. Industrial wearable technologies. (A) Evolution of wearable medical devices (B) Application of wearable devices in the healthcare and biomedical monitoring systems. Reproduced with permission from Hwang, I.; et al. Multifunctional smart skin adhesive patches for advanced health care; Wiley, 2018 [9] and Yao, H.; et al. A contact lens with embedded sensor for monitoring tear glucose level; Elsevier, 2011 [10].

\section{Portable Devices}

From the early 21st century, wearable devices have begun to provide personalized health services, as well as advanced levels of personalized portable devices and sensors. Currently, portable devices 
can be classified as wrists (watches, bracelets and gloves), heads (glasses and helmets), body clothes (coats, underwear and pants), feet, and body sensory control devices (somatosensory modulators) (Figure 2, Table 1) [2,8,14-16]. Due to the miniaturization of biosensing devices, and the development of microelectronics and wireless communication technologies, the wearable monitoring systems deeply embedded in our lives have been further developed [17].

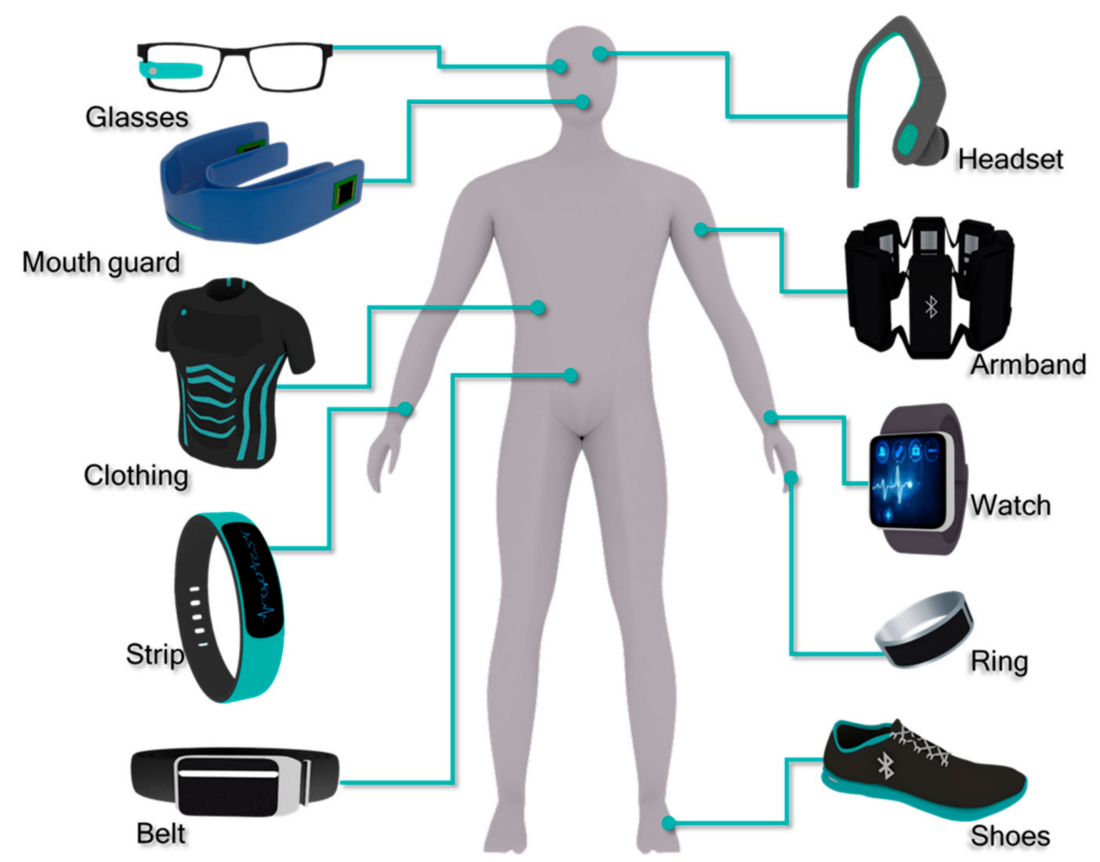

Figure 2. Portable medical and healthcare devices worn on body parts.

\subsection{Wrist-Mounted Devices}

Wrist-mount devices for physiological monitoring have been developed commercially with improvement in battery longevity and miniaturization of hardware for converting raw signals to real-time interpretable data. Wrist-mounted devices, such as fitness bands and smart watches, are moving from basic accelerometer-based "smart pedometers" to include biometric sensing. Typical noninvasive monitoring devices carry out two functions: (1) Communication with electronic devices and (2) monitoring of human physiological signals and human activity signals [15,18].

Blood pressure measurement is one of the most important physiological indicators of an individual's health status [19]. Conventional pulse wave sensors used cuffs to non-invasively monitor blood pressure and included optical, pressure, and electrocardiogram (ECG) sensors. However, these sensors are large in size, difficult to handle, and cannot be accurately measured when the subject moves during blood pressure measurement. To solve this problem, Lee's group developed a wearable device with a Hall device that can detect the minute changes of the magnetic field of the permanent magnet and obtain the pulse wave data. This device can be worn on the wrist, and is a pulsimeter without a cuff [20]. Hsu et al. presented a prototype skin-surface-coupled personal wearable health monitoring system that captures high-fidelity blood pressure waveforms in real time and communicates with wireless devices such as smart phones and laptops [21].

Recently, various applications using a photoelectron imaging (PPG)-based heart rate sensor mounted on the wrist have been proposed [22]. The bracelet-type PPG heart rate sensor developed by Ishikawa et al. detects changes in heart rate and shows the possibility of overcoming motion artifacts in daily activities. Calibration of noise-free heart rate detection was measured using noise reduction pulse signals based on peak detection and autocorrelation methods [15,23].

Smart watches are one of the most popular wearable device types, and GlucoWatch ${ }^{\circledR}$ biographer (Cygnus Inc., Redwood City, CA, USA) is the first to have a commercially approved non-invasive 
glucose monitor by the Food and Drug Administration (FDA) [24]. It electrochemically acquires information about glucose concentration extracted by reverse iontophoresis from skin interstitial fluid. Glennon et al. introduced a watch including fluid systems and storage systems, which can monitor sodium content in the body from sweat in real time [25]. In addition, the wrist-mounted device is applied in the measurement of daily activity including motion, gesture, rotation, acceleration and patient monitoring.

For monitoring of Parkinson's disease (PD) patients, the smart watches can be used to analyze tremor and balance dysfunction with a gyroscope or accelerometer [26]. Roberto's group assessed smart watches for quantification of tremor in PD patients, evaluation of clinical correlation, and its acceptance and reliability as a monitoring instrument. As a result, the smart watch has the possibility as a clinical tool and good acceptance by patients. In addition, Tison's group used the smart devices for developing an algorithm to detect atrial fibrillation (AF) from the data of heart rate measured with PPG sensor and step count with the accelerometer [27]. The main cause of stroke is AF, and patients at risk of stroke can prepare for the disease by continuously monitoring AF.

\subsection{Head-Mounted Devices}

Wearable smart glasses are a type of head-mounted computer that displays information [28]. Smart glasses designed by Nicholas Constant et al. are pulse-sensing glasses containing a photoplethysmography (PPG) sensor on the nose pad to continuously monitor heart rate [29]. Joseph Wang et al. presented eyeglasses comprising nose pads consisting of a lactate biosensor capable of monitoring lactate, as well as a potassium ion-selective electrode that can measure potassium ions from sweat in real time [30]. Smart glasses can also be fabricated with sensors such as accelerometers, gyroscopes, altimeters, barometers, magnetometers and GPSs. The more advanced smart glasses are called Recon Jet, and they aim to capture information about their owner's health status while running or riding a bicycle, by providing information about their activities through the display [31]. Mitsubayashi et al. produced a mouthguard glucose sensor using microelectromechanical systems (MEMS), and includes $\mathrm{Ag} / \mathrm{AgCl}$ and Pt electrodes fabricated with enzyme membrane immobilized glucose oxidase [32]. Kim et al. demonstrated an enzyme-based biosensor integrated mouthguard for detecting salivary uric and lactate $[33,34]$. The enzyme modified system demonstrates high selectivity and sensitivity.

\subsection{E-Textiles}

Smart textiles, or smart clothing, consists of conductive devices and clothing material that is attached to or woven with the conductive devices. Textile-based diagnostic devices incorporate sensors, such as electrodes and fabrics, or by sewing electrodes into fabric [35,36]. The integrated sensors into textiles have been used to analyze biofluids [36]. Smart textiles must include three components. i.e., a sensor, an actuator and a controlling unit [37]. Textile containing electrodes, called e-textiles, are used to monitor human physiological signals, biomechanics and physical activity, such as motion, body acceleration and pressure $[18,38]$.

To measure glucose and lactate with high accuracy, Liu et al. fabricated a glucose and lactate detection system by using glucose oxidase and lactate oxidase-based electrodes in a fabric [36]. In addition, Liu's group developed living material and a glove that has integrated hydrogel-elastomer hybrids integrated with genetically engineered bacteria including genetic circuits, to give materials desirable functions [39]. Chemically different induced cell strains were encapsulated in the chamber of hydrogel, and interaction between the bacteria strains and environment is created via diffusion.

When inducer (IPTG, Rham) is contacted with the bacterial sensor that is programmed fluorescence (IPTGRCV/GFP, RhamRCV/GFP), the fluorescence response is activated. The biosensor with synthetic biology technology has the potential to monitor healthcare and environment as mechanical flexibility and low cost. 
Physiological signals, such as heart rate, breathing rate and temperature, are also monitored using e-textiles [40,41]. The Hexoskin wearable vest is capable of monitoring heart rate and breathing rate during daily activity [42]. An electronic shoe has been developed to measure walking ability, such as lateral plantar pressure, heel strike, toe pressure, and ground reaction forces [43,44], which provide fundamental information for distinguishing among gait phases. Rupesh K. Mishra et al. developed a glove incorporating an electrochemical biosensor with a stretchable printable enzyme-based electrode that is able to detect organophosphate (OP) nerve-agent compounds. The glove consists of an index finger that has a carbon-based counter electrode, working electrodes, an $\mathrm{Ag} / \mathrm{AgCl}$-based reference electrode, and a thumb printed carbon pad. The index finger is a sensing finger that contains an organophosphorus hydrolase layer, and the thumb is a collector/sampling finger. Furthermore, stress-enduring inks are used to print the electrode system and the long serpentine connections to the wireless electronic interface. This lab-on-a-glove is applied as a point-of-use screening tool and in defense and food security applications [45].

\subsection{Others}

Smart jewelry, a wearable real-time monitoring device, is designed to warn users through smartphone alerts whilst tracking smart biomedical signals and biomechanics at the time of payment or performing out ambient sensing [18]. In addition, these wearable devices can track human activity, such as consumed calories and distance travel, and measure quality and duration of sleep [46-48]. Bellabeat Leaf is a smart accessory, such as a necklace, a bracelet, or clip that uses only 3D accelerometers and haptic vibration motors that detects sleep, daily activities, menstrual cycles, and breathing, and do not have commonly used sensors like GPS or a heart rate monitor [49]. The smart belt such as WELT (Wellness Belt) or BELTY monitor information such as waist size, food intake and movement of users like step count, and sitting time [50-52]. As a smart chest strap, OmegaWave has monitoring electrodes providing information of electrocardiogram (ECG) and direct current for assessing the activity of the cardiac system and central nervous system [53]. The Zephyr Bioharness is another chest strap that features reliable real time recording of HR, breathing rate, temperature, ECG and respiratory rate [54]. In particular, respiratory rate is detected by measuring chest expansion and contraction [55].

Table 1. Summary of portable devices.

\begin{tabular}{|c|c|c|c|}
\hline & Monitoring & $\begin{array}{l}\text { Physiological \& Physical } \\
\text { Parameters (Device) }\end{array}$ & Ref. \\
\hline \multirow{2}{*}{$\begin{array}{l}\text { Wrist-mounted } \\
\text { Devices }\end{array}$} & Cardiovascular signal & $\begin{array}{l}\text { heart rate, blood pulse etc. (wrist } \\
\text { band or watch) }\end{array}$ & [20-23] \\
\hline & Sweat contents & $\begin{array}{l}\text { glucose, sodium etc. (wrist band } \\
\text { or watch) }\end{array}$ & {$[24,25]$} \\
\hline \multirow{3}{*}{$\begin{array}{l}\text { Head-mounted } \\
\text { Devices }\end{array}$} & Salivary contents & $\begin{array}{l}\text { lactate, uric acid and glucose etc. } \\
\text { (mouth guard) }\end{array}$ & [32-34] \\
\hline & Sweat contents & $\begin{array}{c}\text { Lactate and potassium etc. } \\
\text { (eyeglasses) }\end{array}$ & {$[30]$} \\
\hline & Cardiovascular signal & heart rate (eyeglasses) & [29] \\
\hline \multirow{3}{*}{ E-Textiles } & Sweat contents & $\begin{array}{l}\text { glucose and lactate etc. (textiles } \\
\text { with electrode) }\end{array}$ & [36] \\
\hline & Cardiovascular signal & $\begin{array}{l}\text { heart rate and temperature etc. } \\
\text { (leg calf) }\end{array}$ & [40-42] \\
\hline & Physical activity & foot motion (footwear) & {$[43,44]$} \\
\hline \multirow{3}{*}{ Others } & Physical activity & $\begin{array}{l}\text { sleep, daily activity etc. (ring, } \\
\text { necklace and clip etc.) }\end{array}$ & [46-49] \\
\hline & Physical activity & $\begin{array}{l}\text { step count and sitting time (belt } \\
\text { worn on waist) }\end{array}$ & {$[51,52]$} \\
\hline & Physiological signal & $\begin{array}{l}\text { ECG and direct current (belt worn } \\
\text { on chest) }\end{array}$ & [53-55] \\
\hline
\end{tabular}




\section{Attachable Devices}

Attachable monitoring devices are considered to be the next-generation personal portable health care devices for remote medical progression. An important feature that defines an attachable device is skin-like adaptability and flexibility, providing accurate and reliable sensing without compromising a user's natural movement and comfort. Flexible thermoplastic polymers such as PC, polyethylene terephthalate (PET) and polyurethane have been selected for flexible materials production due to their excellent optical transparency, ease of manufacture and excellent deformability. In addition to soft substrate-based templates, completely functional, attachable and flexible sensors are essential for active sensing elements-their most important components [56].

With the latest advances in sensor technology, MEMS, microelectronics, data analysis, communications and physiotherapy, attachable devices can be developed. In particular, the miniaturization of electronic circuits using microelectronics has been an important part of the development of attachable devices. In the past, due to the size of sensors and front-end electronic devices, the hardware had difficulty in collecting physiological and biomedical data for long-term monitoring applications. Currently, the development of microelectronics allows the creation of microcontroller functions and wireless transmission-enabled circuits. MEMS also allowed miniaturization that enabled batch manufacturing, and significantly reduced the cost of electronic components [14]. Smart attachable sensing devices are an important component in real-time health monitoring systems for physiological signals that are closely associated to physical conditions such as blood pressure, heart rate, electrophysiology, body temperature and various sweating biomarkers.

\subsection{Wearable Skin Patches}

Wearable skin patches are becoming increasingly pervasive within the wearables market. Soft, flexible and stretchable electronic devices are connected to soft tissue to provide a new platform for robotic feedback and control, regenerative medicine and continuous healthcare [57]. Skin patches are ideal wearables, because they can be obscured by clothing, and can record more accurate data without being disturbed by movement. Wearable patches worn on the human skin have been utilized as cardiovascular, sweat, strain and temperature sensors [58].

\subsubsection{Monitoring of Blood Pressure and Heart Rate}

Monitoring cardiovascular signals such as blood pressure and the heart rate of patients receiving medical care is very important. A thin, flexible and patch-type continuous blood pressure (BP) monitoring sensor is constructed with a layered structure of ferroelectric film, specially designed electrodes and flexible electronic circuits, which together enable simultaneous electrocardiogram (ECG) and ballistocardiogram (BCG) measurements on the human chest without discomfort [59]. In a feasibility study using the developed sensor, the estimates of systolic blood pressure are in good agreement with the reference value, and the correlation coefficient of the class was $0.95(p<0.01)$.

Reported in Advanced Functional Materials, a wearable patch sensor incorporating flexible piezoresistive sensor (FPS) and epidermal ECG sensors for cuffless blood pressure monitoring has been developed [60]. The system simultaneously measures epidermal pulse signals and the ECG and obtains bit-to-bit BP data in real time through the pulse transit time (PTT) method. To obtain a very stable surface pulse signal, a parametric model of the FPS detection mechanism was developed and the operating conditions were optimized. In particular, this sensing patch can operate at ultra-low power $(3 \mathrm{nW})$ and detects subtle physiological changes such as before and after exercise to provide promising solutions for real-time and home-based BP monitoring.

In a recent study, Sheng $\mathrm{Xu}$ and colleagues demonstrated the initial function of a conformal ultrasonic patch to monitor blood pressure waveforms in areas of deep arteries and veins [61]. Ultrasonic waves can penetrate deep into biomechanical tissues, enabling 3D detection of currently worn electronic devices. 
Wearable ultrasonic devices ensure intimate, conformal contact with curved and time-dynamic skin surface, and allows continuous monitoring of CBPs for cardiovascular disease without operational discomfort or instability caused by other traditional methods (Figure 3). The device is built around piezoelectric ultrasound transducers with a $4 \times 5$ arrangement, and is connected to 20 stimulating electrodes respectively. The array is designed to map the position of the vessels so that it can be detected and monitored using a transformer above the target without the need for tedious manual placement.

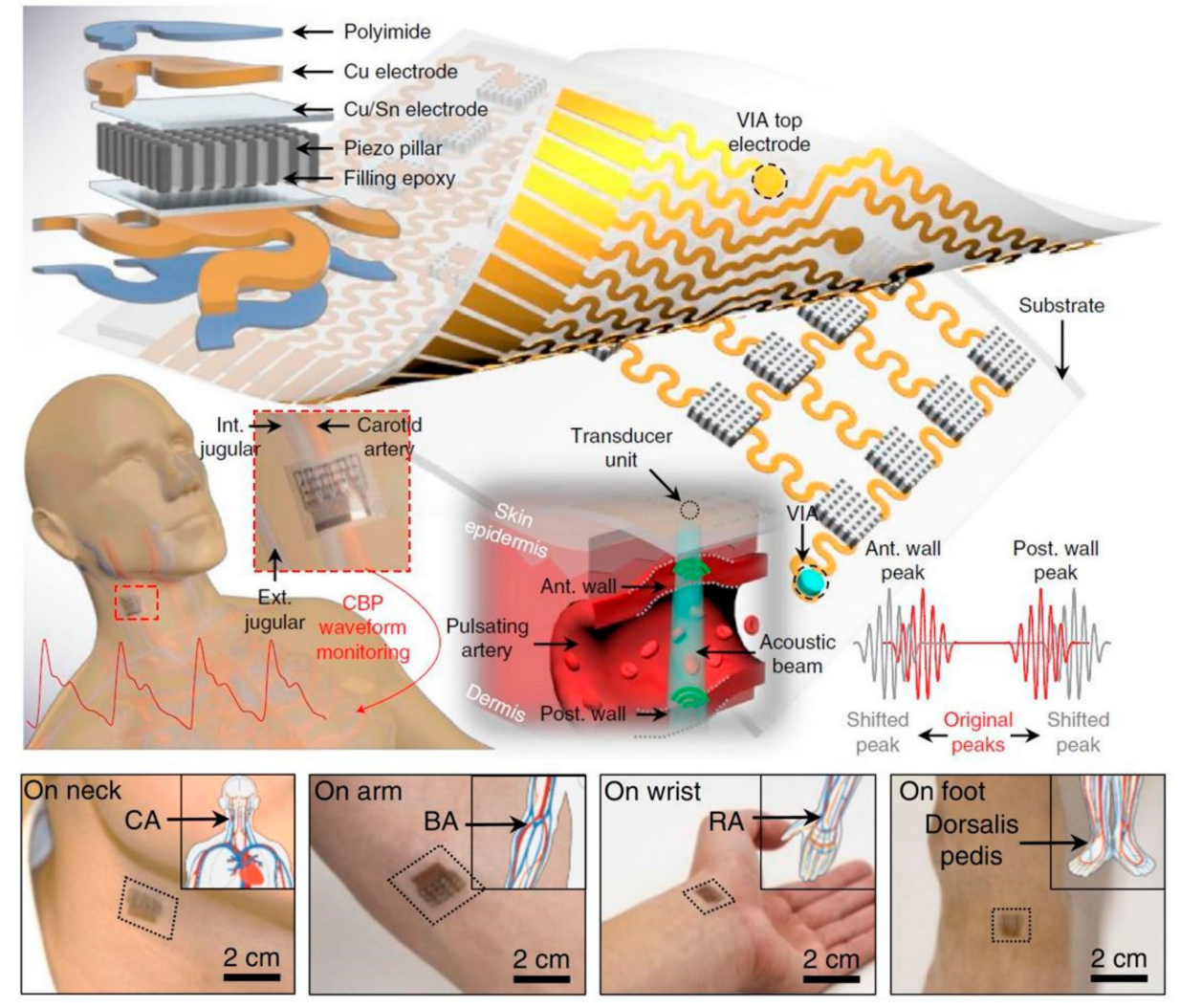

Figure 3. Stretchable ultrasonic device to identify and capture arterial blood-pressure waveforms. The high-performance 1-3 composite with piezoelectric microrods embedded in an epoxy matrix suppresses shear vibration modes and improves ultrasonic penetration into the skin. The wearable device can monitor peripheral vessel hemodynamics at different locations, for example, to sites of the brachial, radial, femoral or dorsalis pedis arteries. Reproduced with permission from Wang, C.; et al. Monitoring of the central blood pressure waveform via a conformal ultrasonic device; Springer Nature, 2018 [61].

The wearable pulse wave monitoring sensor is attached directly to the epidermis, and the fluctuations of the pulse wave can cause the transform of piezoelectric material of sensor (Table 2) [62,63]. D.Y. Park et al. present a self-powered, flexible piezoelectric pulse sensor based on high-quality lead zirconate titanate (PZT) thin film for a real-time arterial pulse monitoring system [64]. Experimental results demonstrate a piezoelectric pressure sensor with a sensitivity of $0.018 \mathrm{kPa}^{-1}$, response time of $60 \mathrm{~ms}$, and remarkable mechanical durability. The developed sensor connected with a wireless blue-tooth transmitter and an Android-based smart phone which could display the detected signals in real time.

Attachable and flexible pulse sensors are designed to detect long-term biological signals [65]. One device was incorporated with microthin inorganic photodetectors (IPDs, thickness: $4.1 \mu \mathrm{m}$ ) and a red light-emitting diode $(620 \mathrm{~nm})$, and is encapsulated into an adhesive elastomer layer. The device operates in a reflective mode and can be attached to various locations on the human body to measure the heart pulse waveforms. Using microstructured polydimethylsiloxane (PDMS) (i.e., pyramid-like patterns) films, Bao et al. introduced a continuous, real-time pressure monitoring system with wireless, 
flexible, passive and millimeter-scale sensors [66]. This monitoring system is used to capture human radial pulse waveforms in real time, as well as to continuously monitor in vivo intracranial pressure in proof-of-concept mice studies. In a recent study, a highly sensitive flexible three-axis tactile sensor is presented by combining micro-pyramid PDMS arrays and a reduced graphene oxide (rGO) film [67].

Table 2. Comparison of advantages and disadvantages of piezoelectric, resistive and capacitive sensors.

\begin{tabular}{|c|c|c|}
\hline & Advantages & Disadvantages \\
\hline $\begin{array}{l}\text { Piezoelectric } \\
\text { sensor }\end{array}$ & $\begin{array}{l}\text { High sensitivity } \\
\text { High mechanical stiffness } \\
\text { Actuation mechanism is highly resistive } \\
\text { to environmental effect } \\
\text { (e.g., humidity, temperature) } \\
\text { Very fast response } \\
\text { Broad frequency range } \\
\text { Excellent repeatability }\end{array}$ & $\begin{array}{l}\text { High impedance } \\
\text { Small displacements } \\
\text { Low material tensile strength } \\
\text { Auxiliary Equipment needed } \\
\text { Limited temperature range }\end{array}$ \\
\hline Resistive sensor & $\begin{array}{l}\text { Bond excellently to most surfaces } \\
\text { Minimal sensitivity to transverse strain } \\
\text { High frequency response } \\
\text { High linearity } \\
\text { Low impedance } \\
\text { Good spatial resolution } \\
\text { Generally unaffected by ambient } \\
\text { conditions } \\
\text { Ability to measure dynamic loads } \\
\text { Simple construction }\end{array}$ & $\begin{array}{l}\text { Temperature sensitive (Gage factor changes } \\
\text { with temperature as well) } \\
\text { compared to piezoresistive sensors strain } \\
\text { gages have much lower sensitivity (typical } \\
\text { gage factor } 2 \text { vs. } 100 \text { for the } \\
\text { piezoresistive sensor) }\end{array}$ \\
\hline $\begin{array}{l}\text { Capacitive } \\
\text { sensor }\end{array}$ & $\begin{array}{l}\text { Be used to detect non-metallic targets } \\
\text { Simple in construction and adjustable } \\
\text { Detect dense targets and liquids } \\
\text { Relatively less costly and small } \\
\text { Higher sensitivity and can be operational with } \\
\text { small magnitude of force } \\
\text { Very good resolution (as low as } 0.003 \mathrm{~mm} \text { ) and } \\
\text { frequency response }\end{array}$ & $\begin{array}{l}\text { Operation needs a clean environment } \\
\text { (a capacitor is affected by temperature, } \\
\text { humidity, pressure, dust, etc.) } \\
\text { The measurement of capacitance is hard } \\
\text { compare to measurement of resistance } \\
\text { Capacitive proximity sensor are not so } \\
\text { accurate compare to inductive sensor type }\end{array}$ \\
\hline
\end{tabular}

\subsubsection{Monitoring of Bodily Fluids}

As a typical body fluid, sweat is especially important because it contains large amounts of important biomarkers, including electrolytes, small molecules, and proteins [68]. Over the past few years wearable sensors have been developed for sweat analysis and have detected various sweat components.

The ultrathin, flexible wireless sweat sensor is installed on functional elastomer substrates, enabling epidermal analysis of biocompatible fluid [69]. This sweat sensor measures the amount of sweat and its chemical properties through the detection of the dielectric and colorimetric. The device contains an inductive coil for stretch and flexibility, and planar capacitors with interdigitated electrodes. The device includes a functional soft substrate that can spontaneously collect sweat through capillary forces without operating any complex microfluidic handling system. Certain components $\left(\mathrm{OH}^{-}, \mathrm{H}^{+}\right.$, $\mathrm{Cu}^{+}$and $\mathrm{Fe}^{2+}$ ) of sweat can be detected in a colorimetric measurement mode by introducing indicator compounds deep in the substrate in the same system.

According to the experimental results, the amount of sweat volume of $0.06 \mu \mathrm{L} / \mathrm{mm}^{2}$ can be accurately measured with high stability and low drift, and color reactions to $\mathrm{pH}$ and various ions provide functions related to sweat analysis.

Continuous and non-invasive biomarker monitoring is important to manage human health, performance and well-being in the field of exercise science and medicine [70]. A wearable electronic sensor capable of simultaneously measuring lactate, hydrogen ions, and sodium ions in human sweat through temperature sensing for internal calibration, is equipped with microfluidic sampling and wireless reading electronics [71]. On the equipment platform, sweat passes through a flexible microneedle sensor array integrated into the microfluidic channel with continuous flow. 
A potentiometric sodium ion sensor has been developed by depositing a polyvinyl chloride membrane into the internal layer of electrochemical deposited poly (3,4-ethylenedioxythiophene) (PEDOT), and the $\mathrm{pH}$ detection layer is based on a high sensitivity of an iridium oxide ( $\mathrm{IrOx}$ ) membrane. The amperometric-based lactate sensor consists of doping enzymes deposited at the top of a semi-penetrating copolymer membrane and outer polyurethane layers, providing good selectivity when various analytes are present.

Tomczak et al. has developed a fully integrated, wearable, flexible and wireless sweat detection device that can measure hydration status continuously and non-invasively by monitoring electrolytes during intense exercise [72]. The main differentiating features of the developed device are as follows: (1) A conformal fluid system that effectively collects sweat from the skin with a high rate of sweat absorption and removes it quickly from the detection area to minimize effects on sweat physiology. (2) Flexible microfluidics and low noise footprint electronics that combine $\mathrm{Na}^{+}$and $\mathrm{K}^{+}$ion selective electrodes to enable wearable, wireless sweat monitoring.

Recently, an electrochemical sensor that can be attached to the skin to detect glucose and $\mathrm{pH}$ in sweat has been studied [73]. Patterned elastic electrodes are manufactured by layering a deposition of carbon nanotubes on a pattern of Au nanosheets filtered on a flexible substrate. The fabricated electrochemical sensors are highly sensitive and selective for both $\mathrm{pH}$ and glucose in sweat because of its close adhesion to the skin using the sticky polymer, Silbione, with mechanical stability corresponding to $30 \%$ stretching and air stability 10 days.

Wearable biosensors developed to monitor noninvasively and constantly target biomarkers, have measured single sample biofluids. Recently, researchers have been working hard to develop an epidermal biomonitoring system that measures two different body fluids (skin interstitial fluid and sweat) using a single wearable sensing platform. This dual specimen collection and epidermal sensing system has been realized through the parallel operation of reverse iontophoretic ISF extraction across the skin and iontophoretic delivery of a sweat-inducing drug (pilocarpine) into the skin at separate sites [74].

Because diabetes is a chronic condition caused by insulin control problems that can lead to various major complications, the patient's glucose levels should be constantly monitored and controlled. Therefore, attachable devices that monitor glucose to improve diabetes management and blood glucose control is very attractive. PDMS dermal patch is a microfluidic sampling system combined with a thermal ablation system that allows noninstrusive control and sampling of glucose or other biomolecules present in interstitial fluids without invasive extraction [75]. Kim's group has created a wearable patch-type sensor made from graphene and gold to enable sweat analysis based diabetes therapy [76]. The flexible devices used gold mesh and gold-doped chemical vapor deposition (CVD) graphene to ensure high conductivity, optical transparency and mechanical reliability for stable electrical signal transmission, and to give translucency such as skin in large deformable device arrays. GP-hybrid sensors use gold-doped CVD graphene as an electrochemically active soft material for enhanced electrochemical activity, selectivity and sensitivity to detect important biomarkers in human sweat. The patch consists of sweat control components (a sweat-uptake layer and waterproof film), sensing components (humidity, glucose, $\mathrm{pH}$ and tremor sensors) and therapeutic components (microneedles, a heater and a temperature sensor) that can be thermally activated to deliver drugs transcutaneously (Figure 4A).

When the relative humidity is detected at the critical sweating point, the temperature and $\mathrm{pH}$ is measured and corrected at the same time. When a high concentration of glucose is measured, the internal heater dissolves the phase-change material and releases Merformin in a feedback percutaneous drug delivery reaction through biocompatible microneedles.

Researchers at Binghamton University at New York State University have developed a new self-powered, disposable and wearable sensor patch that can monitor glucose in human sweat to detect hypoglycemia associated with exercise [77]. This glucose sensing biosensor incorporates a paper-based glucose/oxygen enzymatic fuel cell that is stacked vertically in a standard Band-Aid adhesive patch. 
The paper-based sensors are directly attached to the skin to monitor glucose without external power supply and advanced reading equipment. The calibration curve for the developed sensor with a $10 \mathrm{k} \Omega$ resistor represents a highly linear output signal at 0.02 to $1.0 \mathrm{mg} / \mathrm{mL}$ glucose $\left(\mathrm{R}^{2}=0.989\right)$ with a high sensitivity of $1.35 \mu \mathrm{A} / \mathrm{mM}$.

In a more recent study, Heikenfeld's lab reported complete validation of a blood-correlated sweat biosensing device with integrated sweat stimulation using carbachol as stimulant, microfluidic transport using a hexagonal wick, and an alcohol oxidase [78]. A fully integrated device capable of continuously measuring sweat ethanol, which is accurately correlated with blood ethanol. Eccrine systems, an advanced sweat sensor company, uses Heikenfeld's invention to commercialize this wearable sweat-sensing device. A commercial alcohol biosensor analyses the sweat. The sensor measures concentration of hydrogen peroxide that is generated by metabolizing the ethanol with alcohol oxidase on the enzymatic electrode.

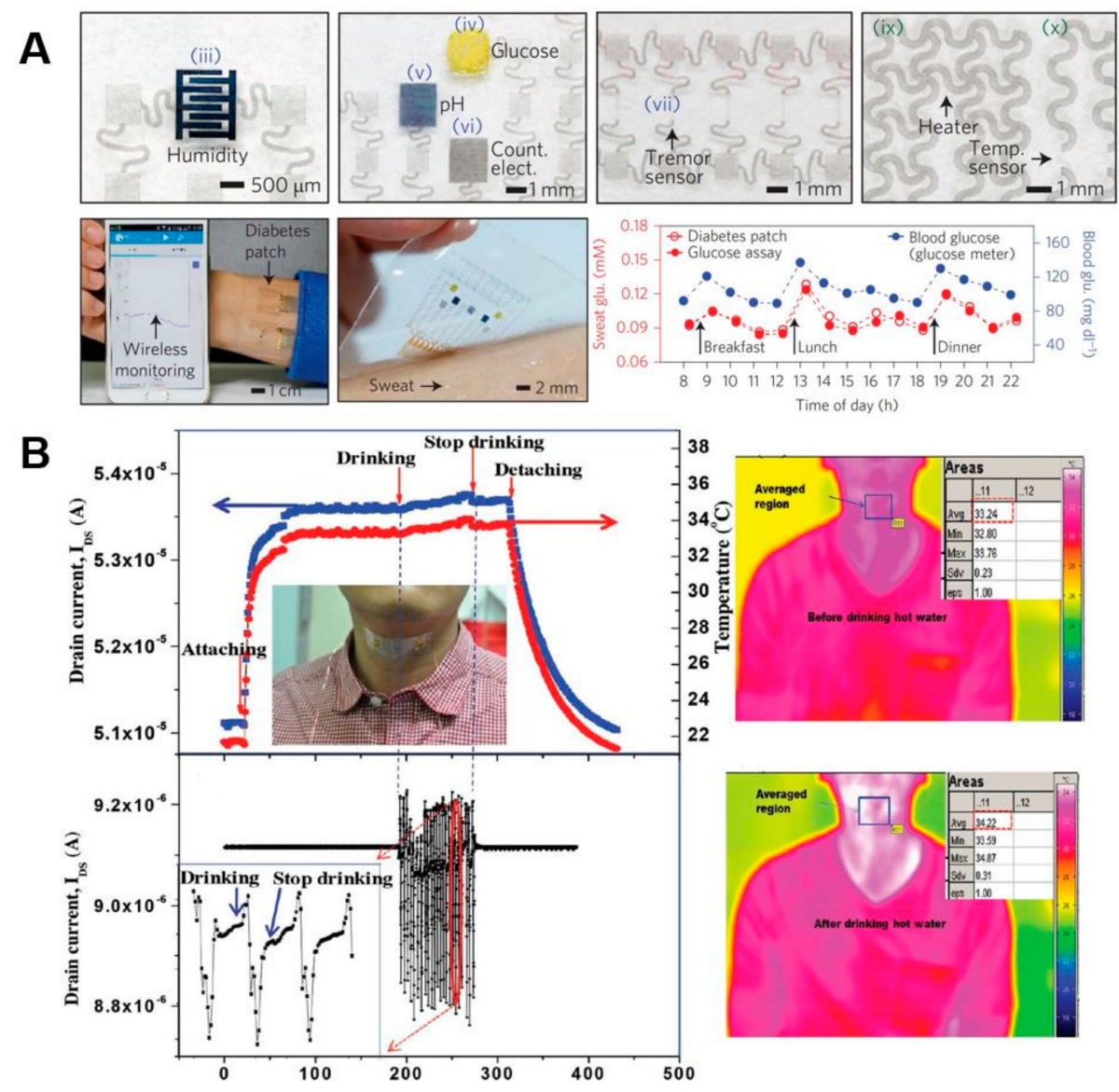

Figure 4. Flexible and stretchable sensing platforms. (A) Optical images of patch consisting of a humidity, glucose, $\mathrm{pH}$, tremor, heater and temperature sensor. The diabetes patch is laminated on the human skin and is connected to a portable electrochemical analyzer with external devices via Bluetooth. Sweat glucose concentrations measured by the diabetes patch (red circles) and a commercial glucose assay kit (red dots) are well matched. In addition, changes in the sweat glucose concentration are well correlated with those of the blood glucose concentration. (B) The transparent and stretchable integrated platform of temperature and strain sensors shows the simultaneous responses to temperature of human skin during muscle movements or drinking of hot water when the integrated sensor platform was placed on the neck of a male subject. Reproduced with permission from Lee, H.; et al. A graphene-based electrochemical device with thermoresponsive microneedles for diabetes monitoring and therapy; Springer Nature, 2016 [76], and Trung, T.Q.; et al. An all-elastomeric transparent and stretchable temperature sensor for body-attachable wearable electronics; Wiley, 2016 [79]. 


\subsubsection{Monitoring of Body Temperature}

It is very important to measure changes in skin temperature during the initial diagnosis and treatment of the disease [80,81]. Rogers's Group demonstrated ultra-thin skin type sensors that can be flexibly attached to the skin surface for continuous and accurate thermal characterization [82]. The ultra-thin and compliant structure of these devices offer significant benefits. First, the skin-like properties are firmly attached to the skin without irritation and are effectively isolated from the strain applied by the sensors/actuators. Second, the thermal mass of the device is extremely low, and its water/gas permeability is high, which is advantageous in terms of response time and thermal loading. The group also developed ultrathin photonic devices by combining colorimetric temperature indicators with wireless flexible electronics. The device used thermochromic liquid crystals formed of a large pixel array on a thin elastomeric substrate [83]. An algorithm that analyzes color patterns recorded on a device using a digital camera, and tools that correlate results with the fundamental heat treatment process of skin surfaces, make the resulting data useful. This epidermal photonic system has a tremendous ability to characterize the skin, and provides important parameters for determining physiological conditions and cardiovascular health.

Reported in Advanced Materials, transparent and stretchable (TS) sensors that simultaneously monitor subtle changes in skin temperature and deformation during human activity are made into a simple process, which can easily be attached as a patch to an object or to the body [79]. The TS-gated and TS-resistive temperature sensing devices exhibited a high sensitivity of approximately $1.34 \%$ per ${ }^{\circ} \mathrm{C}$, and there was no change in response after 1000 cycles of stretching at $30 \%$ strain.

In order to reduce the negative effects of psychological stress upon human society and health, psychological stress should be constantly monitored in daily life. Therefore, researchers have developed a flexible human stress monitoring patch that reduces skin contact area and improves patch wear (Figure 4B) [84]. The human stress monitoring patch is created by integrating three sensors that can track skin temperature, skin conductance, and pulsewaves with stamp size $(25 \mathrm{~mm} \times 15 \mathrm{~mm} \times 72 \mathrm{~mm})$. The development of integrated multi-layered structures and associated micro-manufacturing processes minimizes skin contact areas, resulting in a reduction of $1 / 125$ of the traditional single-layer multiple sensors. The flexibility of the patch has been increased by the invention of a flexible pulse waveform sensor made from flexible piezoelectric membranes supported by perforated polyimide membranes with high chemical resistance and flexibility. The assembled patches measured the skin temperature with a sensitivity of $0.31 \Omega /{ }^{\circ} \mathrm{C}$ for the human physiological range, and the pulse response time was $70 \mathrm{~ms}$.

\subsection{Contact Lens}

Smart contact lenses can monitor the physiological information of the eyes and of any tears non-invasively. Several types of contact lenses using optical and electrical methods have been developed to monitor the chemicals (lactate and glucose) and electrical conductivity of the tear fluid and the transcutaneous gases in the eye's mucous membrane. Alexeev et al. has developed photonic crystals composed of a face-centered cubic arrangement of colloidal particles embedded in hydrogel applied to non-invasive glucose sensing of tear fluid [85]. For glucose sensing at physiologic $\mathrm{pH}$ values, new boronic acid derivatives, such as 4-amino-3-fluorophenylboronic acid (AFBA) and 4-carboxy-3-fluorophenylboronic acid (CFBA), have been used as a molecular recognition agent that combines with glucose to form bis-bidentate cross-links.

In response to the glucose, hydrogel cross linking increases elasticity recoverability, constricts the hydrogel volume, and causes diffraction to blue shift in proportion to the glucose concentration. The color changes that are visualized without any measurement are changed from red to blue in the visible spectrum, depending on the physiological glucose concentration.

A fluorescent contact lens with a hand-held photofluorometer was proposed for the noninvasive monitoring of glucose [86]. The contact lenses were made from liquid hydrogel nanospheres containing tetramethylrhodamine isothiocyanate concanavalin A (TRITC-Con) and fluorescein isothiocyanate 
dextran (FITC-dextran). As the glucose concentration increases, glucose displaces FITC-dextran from the combined position on TRITC-Con A, thereby increasing the fluorescent intensity.

A wearable contact lens optical sensor has been developed to continuously measure glucose in physiological conditions [87]. The sensor is fabricated on the surface of a glucose-sensitive hydrogel network using a simple stamping method, and is attached to commercial contact lenses. Using smartphone applications, the sensor can record the reflectivity of the primary diffraction light, and it demonstrates the benefits of high sensitivity, fast response time and short saturation time (Figure 5).
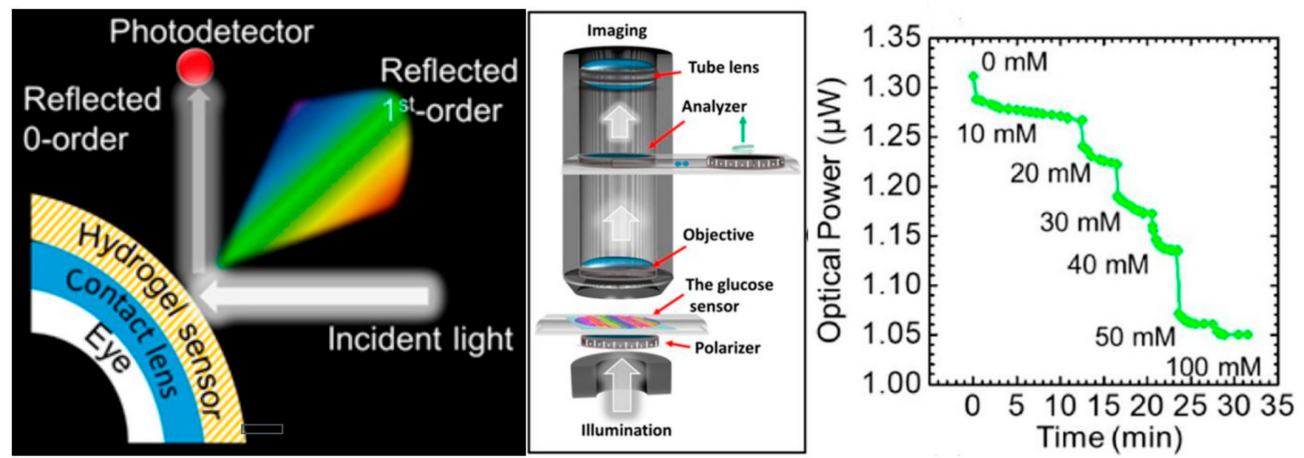

Figure 5. Examples of smart contact lens for detecting glucose. Schematic diagrams of the measurement setup. Continuous monitoring of the reflected power in response to various glucose concentrations (0-50 $\mathrm{mM}$ ) versus time measured using the optical powermeter. Reproduced with permission from Elsherif, M.; et al. Wearable contact lens biosensors for continuous glucose monitoring using smartphones; American Chemical Society, 2018 [87].

The electronic enzyme L-lactate sensor, using contact lenses, is designed to detect L-lactate in the tear fluid potentially at least invasive [88]. The sensor utilizes a functional platinum structure with cross-linking of lactate oxidase, glutaraldehyde and bovine serum albumin, and is coated with medical polyurethane. The sensor can measure the physiological concentration of $\mathrm{L}$ lactate on the tear film based on its fast response time of $35 \mathrm{~s}$, an average sensitivity of $\sim 53 \mu \mathrm{AmM}^{-1} \mathrm{~cm}^{-2}$ within a linear range, and sufficient resolution.

\section{Implantable and Ingestible Devices}

Implantable or implanted devices have recently become an emerging measurement of wireless medical measurement (Table 3). This measurement is possible through the fusion and development of MEMS technology with biology, chemistry, electrical and mechanical technology. Since these devices operate directly in the body, they should be prevented in advance from adverse effects (such as rejection of transplantation) that may affect the human body. Because human tissue is conductive, it can short-circuit the antenna of the device if it is in direct contact with the metal material of the implanted or ingested device [89]. Insertion-type instruments are used to diagnose and treat diseases by detecting changes in the body, and ingested instruments are considered to be suitable for endoscopy because they pass through the digestive system. The wireless remote capability of these devices is essential, not only for transferring patient monitoring data, but also for maintaining the device's battery and status and function upgrades. So researchers have been trying to solve the problems of implantable or consumable devices that will be used in the future (antenna design and performance enhancement, configurable radio frequency settings, power and electronic system modeling). 
Table 3. Summary of the attachable, implantable and ingestible devices for health monitoring.

\begin{tabular}{|c|c|c|c|}
\hline \multicolumn{4}{|c|}{ Attachable Devices } \\
\hline & Monitoring & Physiological Parameters & Ref. \\
\hline \multirow[t]{3}{*}{ Patch } & Cardiovascular signal & $\begin{array}{c}\text { Blood pressure and heart rate by } \\
\text { measuring of ECG, BCG and pulse } \\
\text { transit time with a thin, flexible } \\
\text { patch }\end{array}$ & {$[59-61,65]$} \\
\hline & Chemicals & $\begin{array}{l}\text { Sweat volume and sweat } \\
\text { components like hydration, } \\
\text { glucose, lactate, } \mathrm{pH} \text { and } \\
\text { electrolytes }\end{array}$ & {$[69,71-74,77,90]$} \\
\hline & Body temperature & Body temperature on skin & {$[79,82-84]$} \\
\hline Contact lens & Chemicals & Glucose and lactate in tear fluid & {$[85-88,91]$} \\
\hline \multicolumn{4}{|c|}{ Implantable and Ingestible Devices } \\
\hline & Monitoring & Physiological parameters & Ref. \\
\hline Pace-maker & Cardiovascular signal & Heartbeat for treating arrhythmias & [92-95] \\
\hline Tattoo & Salivary Sweat & $\begin{array}{c}\text { Monitoring respiration and } \\
\text { pathogenic bacteria detection with } \\
\text { tooth enamel } \\
\text { Lactate, glucose, alcohol and } \\
\text { electrolytes (such as ammonium) } \\
\text { with skin worn tattoo }\end{array}$ & [96-100] \\
\hline Bioink & Interstitial fluid & $\begin{array}{c}\text { Glucose, } \mathrm{pH} \text { and electrolytes (such } \\
\text { as sodium) }\end{array}$ & {$[101,102]$} \\
\hline Smart pill & Medicine & $\begin{array}{l}\text { Medicine when drug reaches } \\
\text { stomach with patch }\end{array}$ & [103-105] \\
\hline
\end{tabular}

\subsection{Implantable Devices}

Since cardiac pacemakers were first developed in the 1960s, the number of patients treated with cardiovascular implantable electronic devices, including pacemakers, implantable cardiovascular defibrillators (ICDs) and implantable deep brain stimulators, has been increasing [92,95]. Most implantable devices consist of batteries and biocompatible materials, as well as programmable circuits. The pacemaker is the most well-known implanted medical device for heart patients; the device is used to treat irregular heartbeats known as arrhythmias, and provides low-energy electrical pulses to restore normal rhythm when irregular heartbeats are detected. The ICD is the latest version of the pacemaker that operates in the same manner. Sudden cardiac death (SCD) accounts for half of all deaths from heart disease. If a conventional pacemaker is not able to restore normal rhythm to heart rate, an ICD will provide a high-energy electrical pulse; indeed, the ICD is associated with significant reductions in mortality among patients at high risk of SCD from ventricular arrhythmias. Deep brain stimulation has been introduced as an effective means of treating movement disorders such as Parkinson's disease [93]. The procedures for transplanting deep brain stimulation electrodes require stereotactic surgery aimed at the neurological structure. The targeted electrodes are controlled by an implantable pulse generator (IPG) for deep brain stimulation to provide electrical signals to control movement. The IPG consists of a battery that generates an electrical stimulus and regulates the electronic circuitry, and thus supplies energy to the target neural system [94].

Tattoos are fascinating platforms for monitoring emotions and vital signs. Electronic tattoos (e-tattoos) can be adapted to various skin textures, enabling noninvasive and best attachment methods to the skin. The texture of the tattoo adhesive layer is thoroughly flexible to move with any skin movement, providing natural wearability for the patient and precise data to the physician. Currently, electronic tattoos function as a means of diagnostic and monitoring for primary healthcare providers who want optimum clinical decisions. 
MaApline et al. has developed wireless graphene nanosensors that do not require a power source, using biomaterials such as tooth enamel to remotely detect and monitor bacteria present in breathing or saliva [102]. The advantages of graphene nanosensors are biocompatibility, robustness, optical transparency, biotransferability and flexibility. Because of these features, graphene printing on a water-soluble silk film substrate can serve as a temporary tattoo platform. Graphene nanosensors using antimicrobial peptides have the ability to specifically detect pathogenic bacteria at a single cell level. The Wang group has recently developed a non-invasive test method based on tattooing to monitor the presence of lactate, glucose, ammonia and alcohol in the body. Tattoo biosensors, which measure the concentration of lactate in human sweat in a noninvasive manner, have been developed to monitor electrochemical signals generated by enzymes [96]. A new skin biosensor functionalized with lactic acid oxidase showed linear high specificity up to $20 \mathrm{mM}$ for lactate secreted from the sweat glands. In addition, the tattoo sensor has a flexible feature, so it has a strong durability even when the skin moves repeatedly. In fact, sensors have been applied to analyze the change of lactate in real-time in the sweat glands of subjects with long-term repeated exercise. In contrast, an ammonia potentiometric tattoo sensor uses an ammonium selective polymer membrane, which is based on nonactin ionophores and a solid state reference electrode [97]. Physiological tests using a tattoo biosensor having an ammonium selective polymer membrane showed $\mathrm{NH}_{4}^{+}$values of 0.1 to $1 \mathrm{mM}$. The authors also succeeded in applying a tattoo-based non-invasive device platform to glucose monitoring, which is easy to wear and move with the skin [98]. The tattoo-based blood sugar detection system is formed by the combination of reverse osmotic pressure-derived epileptic glucose, and an enzyme-based current measurement biosensor, and an oxidized enzyme Prussian blue converter is used (Figure 6A). This sensor responds sensitively to a $23 \mathrm{nA} / \mu \mathrm{M}$ glucose concentration, and has a specific response up to $3 \mu \mathrm{M}$. The validation method was performed by attaching a sensor to the subject's skin and detecting changes in blood glucose after eating. The results of this study suggest that tattooing platforms using iontophoresis and biosensing may be effective in diabetes management and non-invasive monitoring using materials other than glucose in the interstitial fluid. Similarly, a wearable iontophoretic-biosensing temporary tattoo system was used to analyze real-time alcohol content from sweat [99]. The tattoo-type biosensor firstly transfers the drug called phyllocarpine to the transdermal preparation to generate sweat, and secondly measures the alcohol in real time using the alcohol-oxidizing enzyme built into the sensor. This biosensor was designed to be very suitable for the human body, and the experimental results showed a clear difference between before and after drinking. The alcohol sensor includes an electronic plate made of a flexible material in a wearable device for wirelessly measuring and controlling data.

Currently, most commercial wearable devices are using straps or adhesive tapes to attach the devices on the human body. The insecure skin-sensor interference makes these devices suffer from limited functionality and signal-to-noise ratio, as well as significant motion artifacts. In order to overcome these problems, researchers developed a low-cost, ultra-thin, tape-free and multifunctional electronic tattoo [106]. The sensor is manufactured by the cut-and-paste method, and has the filament structure, so it has excellent ventilation, and is not inconvenient to wear (Figure 6B). Since the electronic tattoo sensor is thin with a thickness of $1.5 \mu \mathrm{m}$, it can minimize the artificial feeling of moving with the skin. In addition, the electronic tattoo is equipped with various sensors, ECG (ECG) and skin temperature and moisture can be measured at the same time without any signal degradation.

Recently, researchers at Harvard and MIT have developed biosensitive inks (bioinks) that operate using a simple chemical reaction that does not require power for data processing and transmission, and have proven that the body surface itself can be used as a biointerface, namely, an interactive display [102]. Traditional tattoo inks have been replaced by color changing biosensors as the fluid of the interstitial fluid known as tissue fluid changes. The fluid interacts closely with plasma, so the fluid is a good indicator of the concentration of chemicals in the blood at any given time. The researchers examined four biosensors whose inks change color on the skin to monitor $\mathrm{pH}$, glucose and sodium levels. To date, two types of inks have been tested in vitro using pig skin. One is designed 
to monitor the patient's blood glucose levels, and changes from green to brown as the concentration increases. The second type turns light green when an increase in sodium is detected, and chases sodium concentration to prevent dehydration. In another study, Zhao et al. have developed a 3D bio-printing hydrogel ink that can print a programmed bacterial cell with a high resolution of about $30 \mu \mathrm{m}$ on a large $3 \mathrm{~cm}$-sized biomaterial [101]. 3D printing inks contain waterborne, programmed bacterial cells, nutrients, and signal chemicals, with a blend of polymeric micelles and photoinitiators. In order to directly perform 3D printing on a biomaterial, first, a multi-hydrogel ink composed of various kinds of cells or chemicals (Figure 6C) is used to print, and second, ultraviolet rays are irradiated on the printed matter. The engineered bacteria cells can see the new features of the device through 3D printing. Live tattoos are printed on an elastomeric sheet consisting of a double layer of cells (responsive to AHL, Rham or IPTG) that sense various chemicals and are attached to the skin to incorporate various reactions (Figure 6C). Attached tattoos indicate green fluorescence in the corresponding 3D print pattern upon receipt of the chemical.

A

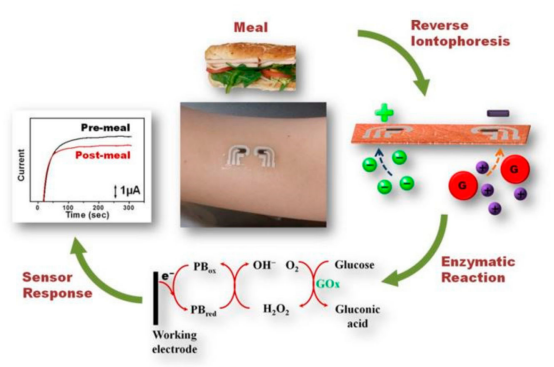

C

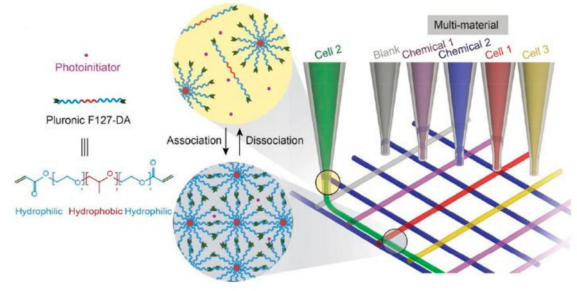

B

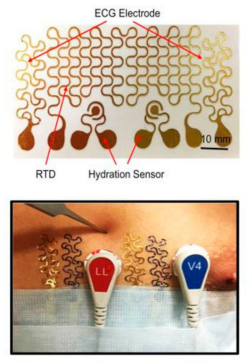

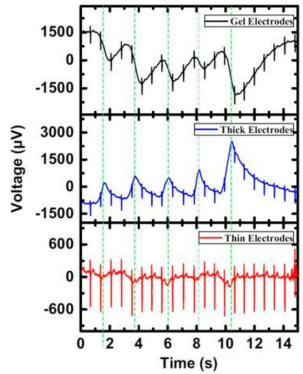

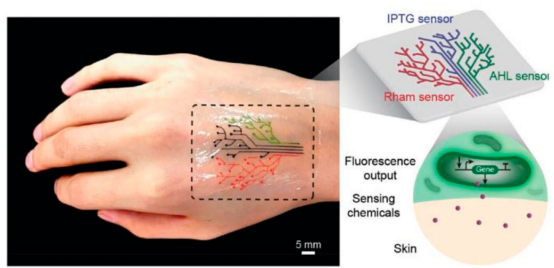

Figure 6. Schematic of implantable devices. (A) Tattoo-based glucose detection platform. (B) Photograph of an e-tattoo incorporating two electrocardiogram (ECG) electrodes, two hydration sensors and an RTD, all in filamentary serpentine (FS) layout. Synchronously measured ECG under skin indentation. (C) Schematic illustration shows direct hydrogel ink writing. The packing of Pluronic F127-DA micelles in the ink leads to a physically crosslinked hydrogel after printing; photoinitiator allows postphotocrosslinking of the living structures after printing; engineered bacterial cells are programmed to sense the signaling chemicals. 3D printed living tattoo is printed as a tree-like pattern on a thin elastomer layer and adhered to human skin. Reproduced with permission from Bandodkar, A.J.; et al. Tattoo-based noninvasive glucose monitoring: A proof-of-concept study; American Chemical Society, 2015 [98], Liu, X.; et al. 3D printing of living responsive materials and devices; Wiley, 2018 [101] and Wang, Y.; et al. Low-cost, $\mu \mathrm{m}$-thick, tape-free electronic tattoo sensors with minimized motion and sweat artifacts; Springer Nature, 2018 [106].

In some cases, implantable devices are no longer managed after a period of treatment. In this case, surgical retrieval procedures are often required, which imposes physical, biological and economical loads on the patient $[107,108]$. Hence, significant efforts from several research groups have afforded bioresorbable electronic implants for elimination of the devices after a certain period of time inside the body.

Recent studies have demonstrated a new class of multifunctional bioresorbable device with built-in optical elements [109], silk-based fully degradable therapeutic devices [110], bioresorbable electronic stent [111], and bioresorbable silicon sensors for the brain [112]. 


\subsection{Ingestible Pills}

A safe, non-invasive approach to accessing the fluid you want to identify is to use an ingestible sensor. This ingestible sensor is able to pass through the lumen of the digestive tract and reach organs around the abdomen. Thus, the ingestion sensor monitors the intrinsic genital contents and lumenal fluid as well as enzymes, hormones, electrolytes, microbial communities and metabolites around the organs and delivers biometric information [113].

Ingestible pills, introduced by Proteus Digital Health (Redwood City, CA, USA), are smart pills for monitoring the precise time at which any drug is taken. When the smart pill reaches the stomach, it is powered up by a chemical reaction with the stomach fluid and sends an ingestion time signal to the patch worn on the body. This patch not only communicates with the smart pill, but also monitors heart rate, blood pressure, $\mathrm{pH}$ and temperature (Figure 7$)[103,105]$. Currently, the most commonly used measure of compliance is indirect measurement through ingestion. My/Treatment/Medication (MyTMed) is a system that can directly check the compliance of drugs [104]. MyTMed consists of an electronic pellet that emits a radio frequency when it comes into contact with an acidic $\mathrm{pH} 2$, and the Hub that receives the radio frequency and sends it to the cloud server, all of this allowing the patient and the doctor to communicate in both directions. The device can be controlled in real time with respect to drug intake information and compliance. Applying the MyTMed system to tablets will make it easier to manage many kinds of chronic diseases.

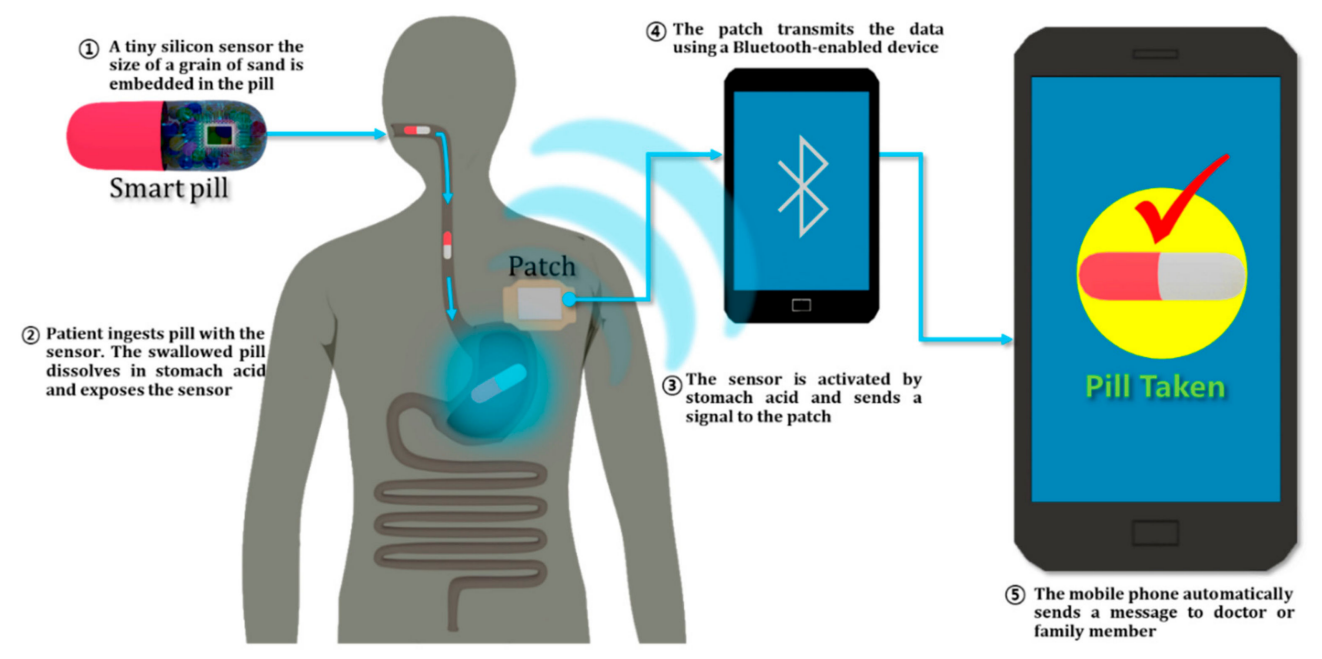

Figure 7. Overview of ingestible pill sensor system.

\section{Conclusions}

Wearable devices are becoming popular in various fields, from healthcare to biomedical monitoring systems (Table 4). In particular, wearable devices are becoming important for long-term health monitoring due to the increasing elderly population throughout the world [114]. In this paper, we have reviewed the latest advances in wearable sensor technologies to identify important biomarkers for noninvasive and possibly continuous monitoring of key diagnostic indicators. Certain technical challenges still need to be addressed for the wide-scale use and deployment of wearable devices as part of the digital health era. One such technical challenge is the personal calibration of wearable devices. The symptoms for early disease diagnosis may differ for every person because every person is unique, and various factors can affect personal health (e.g., family medical history, genetics and diet). Therefore, using a wearable device to monitor a patient's health more accurately and properly requires a machine-based analysis of personal data and a personal calibration of the device. Another challenge is the misalignment of wearables, which affects the quality and accuracy of the measurements. Smarter designs are needed to tolerate such misalignments, for example, by using computational approaches and guide star-like internal references or self-calibration protocols. It is especially important to consider 
the variations in human physiology and the size or 3D conformation of different organs on which wearables operate [115].

Table 4. Application of disease and examples of commercial wearable devices.

\begin{tabular}{|c|c|c|c|}
\hline Disease & Monitoring & Product Category & Commercial Product \\
\hline Metabolic disorder & $\begin{array}{l}\text { Glucose } \\
\text { Hydration }\end{array}$ & $\begin{array}{l}\text { Wrist band/watch } \\
\text { Ear appliance } \\
\quad \text { Patch } \\
\text { Wrist band/watch }\end{array}$ & $\begin{array}{c}\text { GlucoWatch G2 Biographer [24] } \\
\text { Gluco Track } \\
\text { Symphony } \\
\text { Freestyle Libre } \\
\text { Dexcom Patches } \\
\text { LVL }\end{array}$ \\
\hline $\begin{array}{l}\text { Mosquito-borne } \\
\text { diseases }\end{array}$ & $\begin{array}{l}\text { Temperature } \\
\text { Sweat patterns }\end{array}$ & Smart jewelry & TermoTelll bracelet \\
\hline $\begin{array}{l}\text { Skin disease \& UV } \\
\text { related disease }\end{array}$ & Level of UV & $\begin{array}{l}\text { Smart patch } \\
\text { Smart jewelry }\end{array}$ & $\begin{array}{l}\text { MyUV Patch } \\
\text { Netatmo JUNE }\end{array}$ \\
\hline Respiratory diseases & $\begin{array}{c}\text { Audio signal, heart rate, } \\
\text { accelerations } \\
\text { Cardiac electrical activity } \\
\text { (ECG) }\end{array}$ & $\begin{array}{l}\text { Wrist band/watch } \\
\text { Smart patch }\end{array}$ & $\begin{array}{c}\text { LG Watch Urbane W150 } \\
\text { Moto } 360 \text { 2nd Generation } \\
\text { Savvy patch ECG sensor [116] } \\
\text { XYZlife Patch BC1 }\end{array}$ \\
\hline $\begin{array}{l}\text { Skeletal system } \\
\text { diseases }\end{array}$ & $\begin{array}{l}\text { Movement postural } \\
\text { variation gait }\end{array}$ & Smart shoes & $\begin{array}{c}\text { CUR Smart Pain Relief } \\
\text { Valedo } \\
\text { Lumo Lift }\end{array}$ \\
\hline $\begin{array}{c}\text { Sleep or stress related } \\
\text { disease }\end{array}$ & $\begin{array}{c}\text { Heart rate variability, } \\
\text { Heart rate }\end{array}$ & $\begin{array}{l}\text { Wrist watch/band } \\
\text { Smart jewelry } \\
\text { Patch }\end{array}$ & $\begin{array}{c}\text { Airo Health;s anxiety tracker } \\
\text { Oura ring [46] } \\
\text { Motiv ring [47] } \\
\text { Go2Sleep } \\
\text { Kenzen Patch [117] } \\
\text { Vital Scout }\end{array}$ \\
\hline Cognitive disorder & GPS & Wrist band/watch & VegaGPSbracelet \\
\hline $\begin{array}{l}\text { Cardiovascular } \\
\text { disease }\end{array}$ & $\begin{array}{l}\text { Heart rate } \\
\text { Pulse rate }\end{array}$ & Wrist watch/band & HEM serieses of OMRON \\
\hline Fitness tracking & $\begin{array}{l}\text { Heart rate, Calories } \\
\text { burned, activity level } \\
\text { Heart rate, Heart rate } \\
\text { variability, Body } \\
\text { temperature }\end{array}$ & $\begin{array}{l}\text { Smart jewelry } \\
\text { Ear appliance }\end{array}$ & $\begin{array}{l}\text { Ear-o-smart [48] } \\
\text { Cosinuss' One }\end{array}$ \\
\hline Others & Temperature & $\begin{array}{c}\text { Patch } \\
\text { Ear appliance }\end{array}$ & Fever scout degree \\
\hline
\end{tabular}

As the sophistication and miniaturization in field of sensors, battery solution and material science have evolved, wearable biosensors have made many advances in terms of durability and robustness, and further improvements are required in the future. Wearable devices must be able to operate under a variety of conditions, such as in humid or wet environments or at warm temperatures, so that continuous parameter monitoring is possible without compromising performance. Another crucial wearable component that requires increased robustness is the battery, which is particularly important in GPS tracking, consuming a significant amount of battery power. Finally, next-generation wearables will be even smaller than current versions and as their size decreases, the packaging of sensors would be carried out in an integrated manner, so that they do not lose their efficacy in a small area, and can offer slim and even lighter-weight wearable designs.

Over the past few decades, the tremendous advancement of electronics, biocompatible materials and nanomaterials has led to the development of wearable devices that enable the diagnosis and prognosis of small sensors and biomedical devices, greatly improving the quality and efficiency of healthcare services. Future patient monitoring and clinical care will be based on efficient and affordable solutions for wearable devices, enabling remote and long-term patient monitoring in homes and 
communities that were previously impossible. Wearable devices are expected to contribute significantly to the elderly population's health care and medical costs and to the development of personalized medical care.

Funding: This study was supported by the Ministry of Science and ICT (MSIT) Global Frontier Project through the center for BioNano Health-Guard (H-GUARD_2014 M3A6B2060507 and H-GUARD_2013M3A6B2078950), the Basic Science Research Program of the NRF funded by MSIT of Korea (NRF-2018R1C1B6005424 and NRF-2019R1C1C1006867) and by the KRIBB Research Initiative Program of the Republic of Korea.

Conflicts of Interest: The authors declare no conflict of interest.

\section{References}

1. Wearable Sensors Market Worth \$2.86 Billion by 2025 | CAGR: 38.8\%. Available online: http://www. webcitation.org/73HUXmOKl (accessed on 19 October 2018).

2. Pantelopoulos, A.; Bourbakis, N.G. A survey on wearable sensor-based systems for health monitoring and prognosis. IEEE Trans. Syst. Manand Cybern. Part C (Appl. Rev.) 2010, 40,1-12. [CrossRef]

3. Chan, M.; Esteve, D.; Fourniols, J.Y.; Escriba, C.; Campo, E. Smart wearable systems: Current status and future challenges. Artif. Intell. Med. 2012, 56, 137-156. [PubMed]

4. Patel, S.; Park, H.; Bonato, P.; Chan, L.; Rodgers, M. A review of wearable sensors and systems with application in rehabilitation. J. Neuroeng. Rehabil. 2012, 9, 1-17.

5. Kim, J.; Campbell, A.S.; de Ávila, B.E.; Wang, J. Wearable biosensors for healthcare monitoring. Nat. Biotechnol. 2019, 37, 389-406. [CrossRef]

6. Zhu, X.; Liu, W.; Shuang, S.; Nair, M.; Li, C.-Z. Intelligent tattoos, patches, and other wearable biosensors. In Medical Biosensors for Point of Care (poc) Applications; Narayan, R.J., Ed.; Woodhead Publishing: Duxford, UK, 2017; pp. 133-150.

7. Khan, Y.; Ostfeld, A.E.; Lochner, C.M.; Pierre, A.; Arias, A.C. Monitoring of vital signs with flexible and wearable medical devices. Adv. Mater. 2016, 28, 4373-4395. [CrossRef] [PubMed]

8. Bandodkar, A.J.; Wang, J. Non-invasive wearable electrochemical sensors: A review. Trends Biotechnol. 2014, 32, 363-371. [CrossRef]

9. Hwang, I.; Kim, H.N.; Seon, G.M.; Lee, S.H.; Kang, M.; Yi, H.; Bae, W.G.; Kwak, M.K.; Jeong, H.E. Multifunctional smart skin adhesive patches for advanced health care. Adv. Healthc. Mater. 2018, 7, 1800275. [CrossRef] [PubMed]

10. Yao, H.; Shum, A.J.; Cowan, M.; Lähdesmäki, I.; Parviz, B.A. A contact lens with embedded sensor for monitoring tear glucose level. Biosens. Bioelectron. 2011, 26, 3290-3296. [CrossRef]

11. Jeffrey, K.; Parsonnet, V. 1960-1985 a quarter century of medical and industrial innovation. Circulation 1998, 97, 1978-1991. [CrossRef] [PubMed]

12. Gura, M.T. Considerations in patients with cardiac implantable electronic devices at end of life. AACN Adv. Crit. Care 2015, 26, 356-363. [CrossRef] [PubMed]

13. Choi, S.; Lee, H.; Ghaffari, R.; Hyeon, T.; Kim, D.H. Recent advances in flexible and stretchable bio-electronic devices integrated with nanomaterials. Adv. Mater. 2016, 28, 4203-4218. [CrossRef] [PubMed]

14. Gui, H.; Liu, J. Latest progresses in developing wearable monitoring and therapy systems for managing chronic diseases. arXiv 2018, arXiv:1802.01747, 1-30.

15. Kamisalic, A.; Fister, I., Jr.; Turkanovic, M.; Karakatic, S. Sensors and functionalities of non-invasive wrist-wearable devices: A review. Sensors 2018, 18, 1714. [CrossRef]

16. Jiang, H.; Chen, X.; Zhang, S.; Zhang, X.; Kong, W.; Zhang, T. Software for wearable devices: Challenges and opportunities. In Proceedings of the 2015 IEEE 39th Annual Computer Software and Applications Conference, Taichung, Taiwan, 1-5 July 2015; Volume 3, pp. 592-597.

17. Wearable/Portable Health Monitoring System. Available online: http://www.webcitation.org/73HZfChV8 (accessed on 19 October 2018).

18. Seneviratne, S.; Hu, Y.; Nguyen, T.; Lan, G.; Khalifa, S.; Thilakarathna, K.; Hassan, M.; Seneviratne, A. A survey of wearable devices and challenges. IEEE Commun. Surv. Tutor. 2017, 19, 2573-2620. [CrossRef]

19. Khattar, R.S.; Swales, J.D.; Banfield, A.; Dore, C.; Senior, R.; Lahiri, A. Prediction of coronary and cerebrovascular morbidity and mortality by direct continuous ambulatory blood pressure monitoring in essential hypertension. Circulation 1999, 100, 1071-1076. [CrossRef] [PubMed] 
20. Lee, S.-S.; Son, I.-H.; Choi, J.-G.; Nam, D.-H.; Hong, Y.-S.; Lee, W.-B. Estimated blood pressure algorithm for a wrist-wearable pulsimeter using hall device. J. Korean Phys. Soc. 2011, 58, 349-352. [CrossRef]

21. Hsu, Y.-P.; Young, D.J. Skin-surface-coupled personal health monitoring system. In Proceedings of the 2013 IEEE SENSORS, Baltimore, MD, USA, 4-6 November 2013; pp. 1-4.

22. Hwang, S.; Lee, S. Wristband-type wearable health devices to measure construction workers' physical demands. Automat. Constr. 2017, 83, 330-340. [CrossRef]

23. Imai, Y.; Komoriya, Y.; Yoshifuji, K.; Miyashita, K.; Hyodo, Y.; Ishikawa, T. Wearable motion tolerant ppg sensor for instant heart rate in daily activity. In Proceedings of the 10th International Joint Conference on Biomedical Engineering Systems and Technologies, Porto, Portugal, 21-23 February 2017; SCITEPRESS-Science and Technology: Porto, Portugal, 2017; Volume 4, pp. 126-133.

24. Vashist, S.K. Non-invasive glucose monitoring technology in diabetes management: A review. Anal. Chim. Acta 2012, 750, 16-27. [CrossRef]

25. Glennon, T.; O’Quigley, C.; McCaul, M.; Matzeu, G.; Beirne, S.; Wallace, G.G.; Stroiescu, F.; O’Mahoney, N.; White, P.; Diamond, D. 'Sweatch': A wearable platform for harvesting and analysing sweat sodium content. Electroanalysis 2016, 28, 1283-1289. [CrossRef]

26. Lopez-Blanco, R.; Velasco, M.A.; Mendez-Guerrero, A.; Romero, J.P.; Del Castillo, M.D.; Serrano, J.I.; Rocon, E.; Benito-Leon, J. Smartwatch for the analysis of rest tremor in patients with Parkinson's disease. J. Neurol. Sci. 2019, 401, 37-42. [CrossRef]

27. Tison, G.H.; Sanchez, J.M.; Ballinger, B.; Singh, A.; Olgin, J.E.; Pletcher, M.J.; Vittinghoff, E.; Lee, E.S.; Fan, S.M.; Gladstone, R.A.; et al. Passive detection of atrial fibrillation using a commercially available smartwatch. JAMA Cardiol. 2018, 3, 409-416. [CrossRef] [PubMed]

28. Head-Mounted Display-Wikipedia. Available online: http://www.webcitation.org/73HfjH0k9 (accessed on 19 October 2018).

29. Constant, N.; Douglas-Prawl, O.; Johnson, S.; Mankodiya, K. Pulse-glasses: An unobtrusive, wearable HR monitor with internet-of-things functionality. In Proceedings of the 2015 IEEE 12th International Conference on Wearable and Implantable Body Sensor Networks, Cambridge, MA, USA, 9-12 June 2015; pp. 1-5.

30. Sempionatto, J.R.; Nakagawa, T.; Pavinatto, A.; Mensah, S.T.; Imani, S.; Mercier, P.; Wang, J. Eyeglasses based wireless electrolyte and metabolite sensor platform. Lab Chip 2017, 17, 1834-1842. [CrossRef]

31. Barnwell, A. Recon Jet Smartglasses Make you Feel Like Robocop. Available online: http://www.webcitation. org/73HhNRkcs (accessed on 19 October 2018).

32. Arakawa, T.; Kuroki, Y.; Nitta, H.; Chouhan, P.; Toma, K.; Sawada, S.; Takeuchi, S.; Sekita, T.; Akiyoshi, K.; Minakuchi, S.; et al. Mouthguard biosensor with telemetry system for monitoring of saliva glucose: A novel cavitas sensor. Biosens. Bioelectron. 2016, 84, 106-111. [CrossRef] [PubMed]

33. Kim, J.; Imani, S.; de Araujo, W.R.; Warchall, J.; Valdes-Ramirez, G.; Paixao, T.R.; Mercier, P.P.; Wang, J. Wearable salivary uric acid mouthguard biosensor with integrated wireless electronics. Biosens. Bioelectron. 2015, 74, 1061-1068. [CrossRef] [PubMed]

34. Kim, J.; Valdes-Ramirez, G.; Bandodkar, A.J.; Jia, W.; Martinez, A.G.; Ramirez, J.; Mercier, P.; Wang, J. Non-invasive mouthguard biosensor for continuous salivary monitoring of metabolites. Analyst 2014, 139, 1632-1636. [CrossRef]

35. Yetisen, A.K.; Martinez-Hurtado, J.L.; Unal, B.; Khademhosseini, A.; Butt, H. Wearables in medicine. Adv. Mater. 2018, 30, 1706910. [CrossRef]

36. Liu, X.; Lillehoj, P.B. Embroidered electrochemical sensors for biomolecular detection. Lab Chip 2016, 16, 2093-2098. [CrossRef]

37. E-Textiles-Wikipedia. Available online: http://www.webcitation.org/73Hhgelpk (accessed on 19 October 2018).

38. Pacelli, M.; Loriga, G.; Taccini, N.; Paradiso, R. Sensing fabrics for monitoring physiological and biomechanical variables: E-textile solutions. In Proceedings of the 2006 3rd IEEE/EMBS International Summer School on Medical Devices and Biosensors, Cambridge, MA, USA, 4-6 September 2006; pp. 1-4.

39. Liu, X.; Tang, T.C.; Tham, E.; Yuk, H.; Lin, S.; Lu, T.K.; Zhao, X. Stretchable living materials and devices with hydrogel-elastomer hybrids hosting programmed cells. Proc. Natl. Acad. Sci. USA 2017, 114, 2200-2205. [CrossRef] [PubMed]

40. Paradiso, R.; Loriga, G.; Taccini, N. A wearable health care system based on knitted integrated sensors. IEEE Trans. Inf. Technol. Biomed. 2005, 9, 337-344. [CrossRef] 
41. Sibinski, M.; Jakubowska, M.; Sloma, M. Flexible temperature sensors on fibers. Sensors 2010, 10, 7934-7946. [CrossRef] [PubMed]

42. Villar, R.; Beltrame, T.; Hughson, R.L. Validation of the hexoskin wearable vest during lying, sitting, standing, and walking activities. Appl. Physiol. Nutr. Metab. 2015, 40, 1019-1024. [CrossRef]

43. Jung, P.-G.; Oh, S.; Lim, G.; Kong, K. A mobile motion capture system based on inertial sensors and smart shoes. In Proceedings of the 2013 IEEE International Conference on Robotics and Automation, Karlsruhe, Germany, 6-10 May 2013; pp. 692-697.

44. Lee, S.I.; Park, E.; Huang, A.; Mortazavi, B.; Garst, J.H.; Jahanforouz, N.; Espinal, M.; Siero, T.; Pollack, S.; Afridi, M.; et al. Objectively quantifying walking ability in degenerative spinal disorder patients using sensor equipped smart shoes. Med. Eng. Phys. 2016, 38, 442-449. [CrossRef]

45. Mishra, R.K.; Hubble, L.J.; Martin, A.; Kumar, R.; Barfidokht, A.; Kim, J.; Musameh, M.M.; Kyratzis, I.L.; Wang, J. Wearable flexible and stretchable glove biosensor for on-site detection of organophosphorus chemical threats. ACS Sens 2017, 2, 553-561. [CrossRef]

46. Oura Ring. Available online: http://www.webcitation.org/73Hhvd6zT (accessed on 19 October 2018).

47. Motiv Ring. Available online: http://www.webcitation.org/73HiAmChX (accessed on 19 October 2018).

48. Ear-o-Smart. Available online: http://www.webcitation.org/73HiVC389 (accessed on 19 October 2018).

49. Bellabeat. Available online: http://www.webcitation.org/73HitClyl (accessed on 19 October 2018).

50. Nakamura, Y.; Arakawa, Y.; Kanehira, T.; Fujiwara, M.; Yasumoto, K. SenStick: Comprehensive sensing platform with an ultra tiny all-in-one sensor board for IoT research. J. Sens. 2017, 2017, 6308302. [CrossRef]

51. Belty. Available online: http://www.webcitation.org/73Hk5JdTq (accessed on 19 October 2018).

52. Welt. Available online: http://www.webcitation.org/73HjP20cm (accessed on 19 October 2018).

53. Omegawave. Available online: http://www.webcitation.org/73Hkk39gH (accessed on 19 October 2018).

54. Nazari, G.; Bobos, P.; MacDermid, J.C.; Sinden, K.E.; Richardson, J.; Tang, A. Psychometric properties of the zephyr bioharness device: A systematic review. BMC Sports Sci. Med. Rehabil. 2018, 10, 1-8. [CrossRef]

55. Kim, J.H.; Roberge, R.; Powell, J.B.; Shafer, A.B.; Jon Williams, W. Measurement accuracy of heart rate and respiratory rate during graded exercise and sustained exercise in the heat using the zephyr bioharness. Int. J. Sports Med. 2013, 34, 497-501. [CrossRef] [PubMed]

56. Kenry; Yeo, J.C.; Lim, C.T. Emerging flexible and wearable physical sensing platforms for healthcare and biomedical applications. Microsyst. Nanoeng. 2016, 2, 16043. [CrossRef]

57. Liu, Y.; Pharr, M.; Salvatore, G.A. Lab-on-skin: A review of flexible and stretchable electronics for wearable health monitoring. ACS Nano 2017, 11, 9614-9635. [CrossRef] [PubMed]

58. Technology That Is Flexible, Sticky, and Smart=Wearable Patches. Available online: http://www.webcitation. org/73HljLOME (accessed on 19 October 2018).

59. Noh, S.; Yoon, C.; Hun, E.; Yoon, H.N.; Chung, T.J.; Par, K.S.; Kim, H.C. Ferroelectret film-based patch-type sensor for continuous blood pressure monitoring. Electron. Lett. 2014, 50, 143-144. [CrossRef]

60. Luo, N.; Dai, W.; Li, C.; Zhou, Z.; Lu, L.; Poon, C.C.Y.; Chen, S.-C.; Zhang, Y.; Zhao, N. Flexible piezoresistive sensor patch enabling ultralow power cuffless blood pressure measurement. Adv. Funct. Mater. 2016, 26, 1178-1187. [CrossRef]

61. Wang, C.; Li, X.; Hu, H.; Zhang, L.; Huang, Z.; Lin, M.; Zhang, Z.; Yin, Z.; Huang, B.; Gong, H.; et al. Monitoring of the central blood pressure waveform via a conformal ultrasonic device. Nat. Biomed. Eng. 2018, 2, 687-695. [CrossRef] [PubMed]

62. Yang, T.; Jiang, X.; Zhong, Y.; Zhao, X.; Lin, S.; Li, J.; Li, X.; Xu, J.; Li, Z.; Zhu, H. A wearable and highly sensitive graphene strain sensor for precise home-based pulse wave monitoring. ACS Sens. 2017, 2, 967-974. [CrossRef] [PubMed]

63. Xin, Y.; Liu, T.; Sun, H.; Xu, Y.; Zhu, J.; Qian, C.; Lin, T. Recent progress on the wearable devices based on piezoelectric sensors. Ferroelectrics 2018, 531, 102-113. [CrossRef]

64. Park, D.Y.; Joe, D.J.; Kim, D.H.; Park, H.; Han, J.H.; Jeong, C.K.; Park, H.; Park, J.G.; Joung, B.; Lee, K.J. Self-powered real-time arterial pulse monitoring using ultrathin epidermal piezoelectric sensors. Adv. Mater. 2017, 29, 1702308. [CrossRef]

65. Kim, J.; Kim, N.; Kwon, M.; Lee, J. Attachable pulse sensors integrated with inorganic optoelectronic devices for monitoring heart rates at various body locations. ACS Appl. Mater. Interfaces 2017, 9, 25700-25705. [CrossRef] [PubMed] 
66. Chen, L.Y.; Tee, B.C.; Chortos, A.L.; Schwartz, G.; Tse, V.; Lipomi, D.J.; Wong, H.S.; McConnell, M.V.; $\mathrm{Bao}, \mathrm{Z}$. Continuous wireless pressure monitoring and mapping with ultra-small passive sensors for health monitoring and critical care. Nat. Commun. 2014, 5, 5028. [CrossRef]

67. Zhang, J.; Zhou, L.J.; Zhang, H.M.; Zhao, Z.X.; Dong, S.L.; Wei, S.; Zhao, J.; Wang, Z.L.; Guo, B.; Hu, P.A. Highly sensitive flexible three-axis tactile sensors based on the interface contact resistance of microstructured graphene. Nanoscale 2018, 10, 7387-7395. [CrossRef]

68. Sonner, Z.; Wilder, E.; Heikenfeld, J.; Kasting, G.; Beyette, F.; Swaile, D.; Sherman, F.; Joyce, J.; Hagen, J.; Kelley-Loughnane, N.; et al. The microfluidics of the eccrine sweat gland, including biomarker partitioning, transport, and biosensing implications. Biomicrofluidics 2015, 9, 031301. [CrossRef]

69. Huang, X.; Liu, Y.; Chen, K.; Shin, W.J.; Lu, C.-J.; Kong, G.-W.; Patnaik, D.; Lee, S.H.; Cortes, J.F.; Rogers, J.A. Stretchable, wireless sensors and functional substrates for epidermal characterization of sweat. Small 2014, 10, 3083-3090. [CrossRef]

70. Pervasive Sensing for Athletic Training. Available online: https:/www.researchgate.net/publication/ 263059695_Pervasive_sensing_for_athletic_training (accessed on 19 October 2018).

71. Anastasova, S.; Crewther, B.; Bembnowicz, P.; Curto, V.; Ip, H.M.; Rosa, B.; Yang, G.Z. A wearable multisensing patch for continuous sweat monitoring. Biosens. Bioelectron. 2017, 93, 139-145. [CrossRef]

72. Alizadeh, A.; Burns, A.; Lenigk, R.; Gettings, R.; Ashe, J.; Porter, A.; McCaul, M.; Barrett, R.; Diamond, D.; White, P.; et al. A wearable patch for continuous monitoring of sweat electrolytes during exertion. Lab Chip 2018, 18, 2632-2641. [CrossRef]

73. Oh, S.Y.; Hong, S.Y.; Jeong, Y.R.; Yun, J.; Park, H.; Jin, S.W.; Lee, G.; Oh, J.H.; Lee, H.; Lee, S.S.; et al. Skin-attachable, stretchable electrochemical sweat sensor for glucose and $\mathrm{pH}$ detection. ACS Appl. Mater. Interfaces 2018, 10, 13729-13740. [CrossRef]

74. Kim, J.; Sempionatto, J.R.; Imani, S.; Hartel, M.C.; Barfidokht, A.; Tang, G.; Campbell, A.S.; Mercier, P.P.; Wang, J. Simultaneous monitoring of sweat and interstitial fluid using a single wearable biosensor platform. Adv. Sci. 2018, 5, 1800880. [CrossRef] [PubMed]

75. Paranjape, M.; Garra, J.; Brida, S.; Schneider, T.; White, R.; Currie, J. A PDMS dermal patch for non-intrusive transdermal glucose sensing. Sens. Actuators A Phys. 2003, 104, 195-204. [CrossRef]

76. Lee, H.; Choi, T.K.; Lee, Y.B.; Cho, H.R.; Ghaffari, R.; Wang, L.; Choi, H.J.; Chung, T.D.; Lu, N.; Hyeon, T.; Choi, S.H.; et al. A graphene-based electrochemical device with thermoresponsive microneedles for diabetes monitoring and therapy. Nat. Nanotechnol. 2016, 11, 566-572. [CrossRef] [PubMed]

77. Cho, E.; Mohammadifar, M.; Choi, S. A single-use, self-powered, paper-based sensor patch for detection of exercise-induced hypoglycemia. Micromachines 2017, 8, 265.

78. Hauke, A.; Simmers, P.; Ojha, Y.R.; Cameron, B.D.; Ballweg, R.; Zhang, T.; Twine, N.; Brothers, M.; Gomez, E.; Heikenfeld, J. Complete validation of a continuous and blood-correlated sweat biosensing device with integrated sweat stimulation. Lab Chip 2018, 18, 3750-3759. [CrossRef] [PubMed]

79. Trung, T.Q.; Ramasundaram, S.; Hwang, B.U.; Lee, N.E. An all-elastomeric transparent and stretchable temperature sensor for body-attachable wearable electronics. Adv. Mater. 2016, 28, 502-509. [CrossRef] [PubMed]

80. Arora, N.; Martins, D.; Ruggerio, D.; Tousimis, E.; Swistel, A.J.; Osborne, M.P.; Simmons, R.M. Effectiveness of a noninvasive digital infrared thermal imaging system in the detection of breast cancer. Am. J. Surg. 2008, 196, 523-526. [CrossRef]

81. Kennedy, D.A.; Lee, T.; Seely, D. A comparative review of thermography as a breast cancer screening technique. Integr. Cancer Ther. 2009, 8, 9-16. [CrossRef]

82. Webb, R.C.; Bonifas, A.P.; Behnaz, A.; Zhang, Y.; Yu, K.J.; Cheng, H.; Shi, M.; Bian, Z.; Liu, Z.; Kim, Y.S.; et al. Ultrathin conformal devices for precise and continuous thermal characterization of human skin. Nat. Mater. 2013, 12, 938-944. [CrossRef] [PubMed]

83. Gao, L.; Zhang, Y.; Malyarchuk, V.; Jia, L.; Jang, K.I.; Webb, R.C.; Fu, H.; Shi, Y.; Zhou, G.; Shi, L.; et al. Epidermal photonic devices for quantitative imaging of temperature and thermal transport characteristics of the skin. Nat. Commun. 2014, 5, 4938. [CrossRef]

84. Yoon, S.; Sim, J.K.; Cho, Y.H. A flexible and wearable human stress monitoring patch. Sci. Rep. 2016, 6, 23468. [CrossRef]

85. Alexeev, V.L.; Das, S.; Finegold, D.N.; Asher, S.A. Photonic crystal glucose-sensing material for noninvasive monitoring of glucose in tear fluid. Clin. Chem. 2004, 50, 2353-2360. [CrossRef] [PubMed] 
86. March, W.; Lazzaro, D.; Rastogi, S. Fluorescent measurement in the non-invasive contact lens glucose sensor. Diabetes Technol. Ther. 2006, 8, 312-317. [CrossRef] [PubMed]

87. Elsherif, M.; Hassan, M.U.; Yetisen, A.K.; Butt, H. Wearable contact lens biosensors for continuous glucose monitoring using smartphones. ACS Nano 2018, 12, 5452-5462. [CrossRef]

88. Thomas, N.L.; Lähdesmäki, I.; Parviz, B.A. A contact lens with an integrated lactate sensor. Sens. Actuators B Chem. 2012, 162, 128-134. [CrossRef]

89. Kiourti, A.; Psathas, K.A.; Nikita, K.S. Implantable and ingestible medical devices with wireless telemetry functionalities: A review of current status and challenges. Bioelectromagnetics 2014, 35, 1-15. [CrossRef]

90. Koh, A.; Kang, D.; Xue, Y.; Lee, S.; Pielak, R.M.; Kim, J.; Hwang, T.; Min, S.; Banks, A.; Bastien, P.; et al. A soft, wearable microfluidic device for the capture, storage, and colorimetric sensing of sweat. Sci. Transl. Med. 2016, 8, 366ra165. [CrossRef]

91. Park, J.; Kim, J.; Kim, S.Y.; Cheong, W.H.; Jang, J.; Park, Y.G.; Na, K.; Kim, Y.T.; Heo, J.H.; Lee, C.Y.; et al. Soft, smart contact lenses with integrations of wireless circuits, glucose sensors, and displays. Sci. Adv. 2018, 4, eaap9841. [CrossRef] [PubMed]

92. Silverman, B.G.; Gross, T.P.; Kaczmarek, R.G.; Hamilton, P.; Hamburger, S. The epidemiology of pacemaker implantation in the United States. Public Health Rep. 1995, 110, 42-46. [PubMed]

93. Gilbert, F.; Ovadia, D. Deep brain stimulation in the media: Over-optimistic portrayals call for a new strategy involving journalists and scientists in ethical debates. Front. Integr. Neurosci. 2011, 5, 16. [CrossRef]

94. Waln, O.; Jimenez-Shahed, J. Rechargeable deep brain stimulation implantable pulse generators in movement disorders: Patient satisfaction and conversion parameters. Neuromodulation Technol. Neural Interface 2014, 17, 425-430. [CrossRef]

95. Connolly, S.J.; Kerr, C.R.; Gent, M.; Roberts, R.S.; Yusuf, S.; Gillis, A.M.; Sami, M.H.; Talajic, M.; Tang, A.S.L.; Klein, G.J.; et al. Effects of physiologic pacing versus ventricular pacing on the risk of stroke and death due to cardiovascular cause. N. Engl. J. Med. 2000, 342, 1385-1391. [CrossRef]

96. Jia, W.; Bandodkar, A.J.; Valdes-Ramirez, G.; Windmiller, J.R.; Yang, Z.; Ramirez, J.; Chan, G.; Wang, J. Electrochemical tattoo biosensors for real-time noninvasive lactate monitoring in human perspiration. Anal. Chem. 2013, 85, 6553-6560. [CrossRef]

97. Guinovart, T.; Bandodkar, A.J.; Windmiller, J.R.; Andrade, F.J.; Wang, J. A potentiometric tattoo sensor for monitoring ammonium in sweat. Analyst 2013, 138, 7031-7038. [CrossRef]

98. Bandodkar, A.J.; Jia, W.; Yardimci, C.; Wang, X.; Ramirez, J.; Wang, J. Tattoo-based noninvasive glucose monitoring: A proof-of-concept study. Anal. Chem. 2015, 87, 394-398. [CrossRef] [PubMed]

99. Kim, J.; Jeerapan, I.; Imani, S.C.; Cho, T.N.; Bandodkar, A.; Cinti, S.; Mercier, P.P.; Wang, J. Noninvasive alcohol monitoring using a wearable tattoo-based iontophoretic-biosensing system. ACS Sens. 2016, 1, 1011-1019. [CrossRef]

100. Mannoor, M.S.; Tao, H.; Clayton, J.D.; Sengupta, A.; Kaplan, D.L.; Naik, R.R.; Verma, N.; Omenetto, F.G.; McAlpine, M.C. Graphene-based wireless bacteria detection on tooth enamel. Nat. Commun. 2012, 3, 763. [CrossRef]

101. Liu, X.; Yuk, H.; Lin, S.; Parada, G.A.; Tang, T.C.; Tham, E.; de la Fuente-Nunez, C.; Lu, T.K.; Zhao, X. 3d printing of living responsive materials and devices. Adv. Mater. 2018, 30, 1704821. [CrossRef] [PubMed]

102. Vega, K.; Jiang, N.; Liu, X.; Kan, V.; Barry, N.; Maes, P.; Yetisen, A.; Paradiso, J. The dermal abyss: Interfacing with the skin by tattooing biosensors. In Proceedings of the 2017 ACM International Symposium on Wearable Computers, Maui, HI, USA, 11-15 September 2017; pp. 138-145.

103. Smartpill ${ }^{\mathrm{TM}}$ Motility Testing System. Available online: http://www.webcitation.org/73HmImC2N (accessed on 19 October 2018).

104. Chai, P.R.; Rosen, R.K.; Boyer, E.W. Ingestible biosensors for real-time medical adherence monitoring: Mytmed. In Proceedings of the 2016 49th Hawaii International Conference on System Sciences, Koloa, HI, USA, 5-8 January 2016; pp. 3416-3423.

105. U.S. FDA Accepts First Digital Medicine New Drug Application for Otsuka and Proteus Digital Health. Available online: http://www.webcitation.org/73Hm3Tnix (accessed on 19 October 2018).

106. Wang, Y.; Qiu, Y.; Ameri, S.K.; Jang, H.; Dai, Z.; Huang, Y.; Lu, H. Low-cost, $\mu$ m-thick, tape-free electronic tattoo sensors with minimized motion and sweat artifacts. NPJ Flex. Electron. 2018, 2, 6. [CrossRef]

107. Kang, S.K.; Koo, J.; Lee, Y.K.; Rogers, J.A. Advanced materials and devices for bioresorbable electronics. Acc. Chem. Res. 2018, 51, 988-998. [CrossRef] 
108. Cha, G.D.; Kang, D.; Lee, J.; Kim, D.H. Bioresorbable electronic implants: History, materials, fabrication, devices, and clinical applications. Adv. Healthc. Mater. 2019. [CrossRef] [PubMed]

109. Tao, H.; Kainerstorfer, J.M.; Siebert, S.M.; Pritchard, E.M.; Sassaroli, A.; Panilaitis, B.J.B.; Brenckle, M.A.; Amsden, J.J.; Levitt, J.; Fantini, S.; et al. Implantable, multifunctional, bioresorbable optics. Proc. Natl. Acad. Sci. USA 2012, 109, 19584-19589. [CrossRef]

110. Tao, H.; Hwang, S.W.; Marelli, B.; An, B.; Moreau, J.E.; Yang, M.; Brenckle, M.A.; Kim, S.; Kaplan, D.L.; Rogers, J.A.; et al. Silk-based resorbable electronic devices for remotely controlled therapy and in vivo infection abatement. Proc. Natl. Acad. Sci. USA 2014, 111, 17385-17389. [CrossRef] [PubMed]

111. Son, D.; Lee, J.; Lee, D.J.; Ghaffari, R.; Yun, S.; Kim, S.J.; Lee, J.E.; Cho, H.R.; Yoon, S.; Yang, S.; et al. Bioresorbable electronic stent integrated with therapeutic nanoparticles for endovascular diseases. ACS Nano 2015, 9, 5937-5946. [CrossRef]

112. Kang, S.K.; Murphy, R.K.; Hwang, S.W.; Lee, S.M.; Harburg, D.V.; Krueger, N.A.; Shin, J.; Gamble, P.; Cheng, H.; Yu, S.; et al. Bioresorbable silicon electronic sensors for the brain. Nature 2016, 530, 71-76. [CrossRef] [PubMed]

113. Kalantar-Zadeh, K.; Ha, N.; Ou, J.Z.; Berean, K.J. Ingestible sensors. ACS Sens. 2017, 2, 468-483. [CrossRef]

114. Haghi, M.; Thurow, K.; Stoll, R. Wearable devices in medical internet of things: Scientific research and commercially available devices. Healthc. Inform. Res. 2017, 23, 4-15. [CrossRef] [PubMed]

115. Koydemir, H.C.; Ozcan, A. Wearable and implantable sensors for biomedical applications. Annu. Rev. Anal. Chem. 2018, 11, 127-146. [CrossRef]

116. Tomasic, I.; Tomasic, N.; Trobec, R.; Krpan, M.; Kelava, T. Continuous remote monitoring of COPD patients-justification and explanation of the requirements and a survey of the available technologies. Med. Biol. Eng. Comput. 2018, 56, 547-569. [CrossRef] [PubMed]

117. Kenzen Patch. Available online: http://www.webcitation.org/73HntSn0b (accessed on 19 October 2018).

(C) 2019 by the authors. Licensee MDPI, Basel, Switzerland. This article is an open access article distributed under the terms and conditions of the Creative Commons Attribution (CC BY) license (http://creativecommons.org/licenses/by/4.0/). 